\title{
Sistemas Nacionais de Inteligência: Origens, Lógica de Expansão e Configuração Atual*
}

\author{
Marco Cepik
}

\section{INTRODUÇÃO}

S istemas governamentais de inteligência consistem em organizadisseminação de informações sobre problemas e alvos relevantes para a política externa, a defesa nacional e a garantia da ordem pública de um país. Serviços de inteligência são órgãos do Poder Executivo que trabalham prioritariamente para os chefes de Estado e de governo e, dependendo de cada ordenamento constitucional, para outras autoridades da administração pública e mesmo do Parlamento. São organizações que desempenham atividades ofensivas e defensivas na área de informações, em contextos adversariais em que um ator tenta compelir o outro à sua vontade. Nesse sentido, pode-se dizer que essas organizações de inteligência formam, juntamente com as

\footnotetext{
* Este texto, com ligeiras modificações, corresponde ao capítulo 2 de minha tese de doutorado, Serviços de Inteligência: Agilidade e Transparência como Dilemas de Institucionalização, defendida e aprovada junto ao Instituto Universitário de Pesquisas do Rio de Janeiro - IUPERJ em 2001. A pesquisa que deu origem a este trabalho foi financiada pela Coordenação de Aperfeiçoamento de Pessoal de Nível Superior - CAPES e pelo Conselho Nacional de Desenvolvimento Científico e Tecnológico - CNPQ.
}

DADOS - Revista de Ciências Sociais, Rio de Janeiro, Vol. 46, nํ1, 2003, pp. 75 a 127. 
Forças Armadas e as polícias, o núcleo coercitivo do Estado contemporâneo ${ }^{1}$.

Serviços de inteligência não são meros instrumentos passivos dos governantes, agentes perfeitos da vontade de seus dirigentes ou mesmo materializações de um tipo ideal de burocracia racional-legal weberiana. Antes de tudo, porque sua atuação impacta as instituições e o processo político de muitas formas e porque essas organizações têm seus próprios interesses e opiniões acerca de sua missão. Embora o tema da intervenção dos serviços de inteligência e de segurança na vida política mais geral seja de grande interesse, tratar os serviços de inteligência como variáveis independentes que influenciam as instituições políticas tende a ser um esforço frustrante quando se sabe tão pouco sobre a origem e o desenvolvimento desses serviços ${ }^{2}$. Por isso, no texto que segue os serviços de inteligência serão considerados como variáveis dependentes. Como não existem ainda estudos sistemáticos sobre o processo através do qual os serviços de inteligência chegaram ou poderiam chegar a tornar-se organizações dotadas de "valor e estabilidade", ou seja, instituições, o procedimento expositivo adotado procurará responder sistematicamente à pergunta sobre a origem, o desenvolvimento e a atual configuração organizacional dos sistemas nacionais de inteligência, mas sem deixar de explicitar as lacunas existentes no conhecimento a respeito ${ }^{3}$.

\section{O ESTADO MODERNO E A FUNÇÃO DE INTELIGÊNCIA}

As primeiras organizações permanentes e profissionais de inteligência e de segurança surgiram na Europa moderna a partir do século XVI, no contexto de afirmação dos Estados nacionais como forma predominante de estruturação da autoridade política moderna ${ }^{4}$.

Como se sabe, o processo de afirmação dos Estados nacionais europeus foi marcado por importantes conflitos sociais, descontinuidades históricas e uma intensa competição entre os Estados nacionais e destes Estados com outros tipos de unidades políticas, particularmente os impérios, as cidades-estado e as ligas de cidades. A melhor explicação disponível sobre essa dinâmica é fornecida por Charles Tilly, em seu livro Coerção, Capital e Estados Europeus (1996) 5 .

O argumento de Tilly pode ser assim resumido: a posse concentrada de meios de coerção foi utilizada por grupos sociais previamente do- 
minantes na ordem feudal, em alguns casos aliados à burguesia ascendente nas cidades, para aumentar a população e o território sobre os quais pretendiam exercer poder. A gênese desse processo está relacionada a pressões impostas pelos califados árabes e pelas movimentações de povos na estepe oriental da Europa, que forçaram os governantes europeus a redefinirem competitivamente suas bases de dominação política e sua infra-estrutura econômica. Quando uma coalizão que tentava expandir sua base de recursos encontrou grupos com meios de força comparáveis e que tornavam muito elevados os custos da dominação, a guerra foi o mecanismo de resolução do impasse.

Conquistadores transformaram-se em governantes quando tentaram exercer um controle estável sobre as populações e territórios cada vez mais extensos, única forma de garantir o acesso regular aos bens e serviços ali produzidos. Nas diversas regiões da Europa e depois do mundo, os governantes mais poderosos fixaram os termos da guerra, e coube aos governantes menos poderosos escolher entre a acomodação e o esforço extenuante de preparação para a mesma.

Para todos os governantes, a guerra e a preparação para a guerra dependiam da extração de recursos essenciais (dinheiro, soldados, provisões, armas etc.) que suas populações não estavam dispostas a entregar sem compensações ou, no mínimo, o fariam a um elevado custo político. Assim, além dos limites estabelecidos pela dinâmica conflitiva entre as diversas unidades políticas mais ou menos similares, a forma de organização política interna de cada Estado foi condicionada pela estruturação das principais classes sociais e, principalmente, pelos conflitos entre os grupos sociais e de alguns daqueles grupos sociais (especialmente proprietários e trabalhadores) com as elites políticas governantes. Na medida em que os custos da guerra aumentaram e os conflitos sociais intensificaram-se com a industrialização, os construtores de Estados (state-builders) foram compelidos a barganhar direitos políticos e favores econômicos por recursos, que variaram de impostos à prestação de serviço militar. Essa barganha foi em grande medida tornada irreversível por sua fixação legal e transformação em costume quase-legal e esteve na gênese do que hoje se chama cidadania.

No entanto, o tipo de Estado que predominou em cada período e região dependeu da combinação entre diferentes taxas de acumulação e concentração de meios de coerção (controlados pelos governantes) e 
taxas igualmente variáveis de acumulação e concentração de capital (controlado por agentes privados). Em distintas regiões da Europa, os governantes utilizaram estratégias extrativas e de dominação que podem ser caracterizadas como de intensa aplicação de coerção (áreas de poucas cidades e predominância agrícola) ou como de intensa inversão de capital (áreas de muitas cidades e predominância comercial, com produção voltada para o mercado). As variadas estratégias de intensa coerção e de "coerção capitalizada" poderiam ajudar a entender, ainda que remotamente, as dessemelhanças doutrinárias e organizacionais entre os primeiros serviços de inteligência e segurança surgidos, por exemplo, na Rússia e na Inglaterra no século XVI.

A variação na escala da guerra, bem como a formação, a partir do século XVII, de um sistema europeu de Estados soberanos foram dois fatores determinantes para a vantagem comparativa daqueles Estados que apresentaram trajetórias de "coerção capitalizada". Segundo Tilly (1996:45-88), esse tipo de percurso ocorreu quando coalizões de burocratas, capitalistas e estadistas foram mais eficientes na gestão da guerra, beneficiaram-se de instituições jurídicas e administrativas mais fortemente racionalizadas, mantiveram-se mais estavelmente associados às classes sociais através da constitucionalização do exercício do poder e estiveram mais intensamente envolvidos na construção de infra-estrutura econômico-social, provimento de serviços e adjudicação de conflitos.

Ao cabo desse processo, já bem avançado o século XIX, os diversos tipos de Estados começaram a convergir para o que passou então a ser reconhecido como o modelo de Estado nacional soberano, caracterizado pela autoridade exclusiva e constitucionalmente delimitada sobre um território e uma população, bem como pelo monopólio do uso legítimo da força. Eventualmente, a resultante dessas várias interações levou à prolongada hegemonia dos Estados capitalistas com sistemas políticos democráticos no sistema internacional, primeiro com a Inglaterra, depois com os Estados Unidos ${ }^{6}$.

Este é um tipo de narrativa sobre o surgimento e a mudança institucional que combina uma dinâmica evolutiva (a guerra como mecanismo de seleção) com uma forte ênfase intencional (interação entre grupos sociais delimitados produzindo conseqüências mais ou menos desejáveis sobre normas e organizações adaptativas). Como lembra Robert Goodin (1996:24-37), é inegável que o acaso e os acidentes 
também jogam um papel no desenho institucional de políticas, mecanismos sociais e sistemas. Porém, mesmo nos casos em que esse papel é mais evidente, é difícil isolar o puro acaso daquilo que são as conseqüências não intencionais de ações perfeitamente racionais, ou daquilo que são resultados agregados de interações entre diversos atores, resultados estes que diferem das intenções iniciais de qualquer ator em particular. É extremamente difícil precisar a exata combinação entre acaso, evolução e intencionalidade no desenho inicial e na trajetória de qualquer organização ou procedimento, seja ele o Estado moderno ou os serviços de inteligência ${ }^{7}$.

Feita a ressalva, assumo provisoriamente que o surgimento dos serviços de inteligência modernos foi predominantemente um fenômeno causado por atos intencionais. Os reis e ministros dos Estados europeus modernos, em seu processo de competição com outros governantes e no esforço de implementar sua dominação sobre territórios e populações cada vez mais amplos, mobilizaram recursos e fundaram organizações especializadas na obtenção de informações. A criação de serviços secretos (mais tarde conhecidos como serviços de inteligência) foi uma das respostas às necessidades mais gerais dos governantes em termos de redução dos custos de transação associados à obtenção de informações.

Do ponto de vista das explicações disponíveis sobre por que organizações e instituições surgem, a constituição de serviços de inteligência pode ser interpretada, em parte, como um resultado direto do puro cálculo estratégico de governantes perseguindo fins previamente dados (vencer a guerra e ampliar sua dominação) e, em parte, como uma resultante mais ou menos imprevisível do esforço desses mesmos governantes para adequarem seus fins a um contexto situacional que precisava ser mais bem compreendido e no qual seu próprio papel enquanto sujeitos políticos interessados era pouco claro ${ }^{8}$. Em um ambiente internacional altamente competitivo, incerto e marcado por altos custos de obtenção de informações necessárias à compreensão das intenções e capacidades de outros atores relevantes, os governantes modernos lançaram mão de vários instrumentos que pudessem reduzir tais custos, desde casamentos e outras formas de alianças dinásticas até o uso de serviços secretos.

Dada a trajetória de afirmação do Estado moderno descrita por Charles Tilly, proposições adicionais sobre a natureza das novas organiza- 
ções de inteligência deveriam considerar não apenas sua função primária (prover informações), mas também as funções secundárias associadas ao uso dessas informações para a dominação e a maximização de poder em diferentes períodos e contextos nacionais. Nesse sentido, os serviços de inteligência modernos teriam surgido com uma dupla face, informacional e coercitiva a um só tempo. Essa dupla natureza caracteriza ainda hoje os sistemas nacionais de inteligência existentes. É preciso reconhecer, porém, que há pouca evidência histórica disponível para ilustrar essa suposição, especialmente no período que vai do século XVI ao final do século XVIII. Mesmo do ponto de vista teórico, os dois autores contemporâneos mais importantes que mencionam algo a respeito tendem a enfatizar características e funções opostas.

Por um lado, Anthony Giddens discute, em seu livro The NationalState and Violence (1987), como o controle governamental de informações relevantes sobre a população e os recursos de cada país foi crucial para a gênese e a consolidação da autoridade soberana do Estado nacional, tanto no plano interno como no plano internacional ou sistêmico. Por outro lado, Tilly menciona o papel dos serviços de inteligência enquanto um meio direto de coerção:

"Governantes [...] enfrentaram alguns problemas comuns, mas o fizeram de modo diferente. Forçosamente, distribuíram os meios de coerção de forma desigual por todos os territórios que tentaram controlar. Na maioria das vezes, concentraram a força no centro e nas fronteiras, tentando manter a sua autoridade entre um e outro por meio de grupos coercivos secundários, leais aplicadores locais de coerção, patrulhas volantes, e pela disseminação de órgãos de inteligência" (1996:72).

Note-se que Tilly enfatiza a função coercitiva em detrimento do papel informacional dos órgãos de inteligência, enquanto Giddens fala da importância dos sistemas de informação indiferenciadamente, sem atentar para o que há de específico no caso dos serviços de inteligência9. Como o foco de ambos é o Estado moderno e não os serviços de inteligência, é compreensível que tenham destacado apenas a faceta do fenômeno que servia mais imediatamente a seus propósitos.

No caso do comentário de Tilly, entretanto, há dois riscos mais sérios. Em primeiro lugar, tratar os serviços de inteligência genericamente como organizações repressivas impede que se compreendam suas es- 
pecificidades (o papel central do segredo e do conhecimento) em relação às principais organizações de força do Estado, tais como as Forças Armadas e as polícias. Em segundo lugar, há o risco de se tratar os serviços de inteligência contemporâneos como se fossem mera continuidade das primeiras organizações modernas, que teriam surgido totalmente prontas e imutáveis como resultado da vontade de poder de déspotas iluminados ${ }^{10}$.

Na verdade, a trajetória moderna dos serviços de inteligência é marcada por grandes descontinuidades entre os primeiros serviços secretos surgidos no contexto do absolutismo e as inúmeras organizações que configuram atualmente os sistemas nacionais de inteligência e segurança. É justamente essa diversidade de funções e perfis organizacionais que torna equivocado caracterizar os serviços de inteligência exclusivamente como organizações de força do Estado. Como parte do núcleo coercitivo do Estado contemporâneo, os serviços de inteligência desempenham um papel predominantemente informacional, com algumas funções explicitamente coercitivas sendo desempenhadas por unidades específicas do sistema.

Além da descontinuidade histórica e da diversidade de funções exercidas por diferentes componentes dos sistemas nacionais, um outro problema na caracterização dos modernos serviços de inteligência é que as macrofunções desempenhadas por eles são apenas uma parte da explicação sobre por que eles surgiram e qual é o seu perfil organizacional atual. A outra parte da explicação é política, não funcional. Para Amy Zegart (1999:42), o desenho inicial e o desenvolvimento posterior de organizações na área de segurança nacional seriam fortemente condicionados por três fatores, em ordem decrescente de importância: a) as escolhas estruturais feitas quando do surgimento da agência; b) os interesses e preferências cambiantes dos atores relevantes; c) os eventos externos que, dependendo da intensidade e do timing, podem forçar uma mudança organizacional.

A formação dos sistemas nacionais de inteligência acompanhou as linhas mais gerais da delimitação de identidades nacionais, construção do Estado (state-building), institucionalização democrática, utilização de sistemas de informação e usos de meios de força na era moderna. Mas, para ir além da contextualização proporcionada pelo livro de Charles Tilly, é necessário conhecer não apenas os resultados contingentes de inúmeros conflitos político-burocráticos no momento do 
surgimento de cada organização, mas também como os atores relevantes modificaram seus interesses, preferências e cálculos de custo e benefício diante dos eventos decisivos que marcaram a trajetória de cada organização. É preciso, também, ser capaz de reconhecer os diferentes ritmos da formação de sistemas nacionais e, dentro de cada país, como o "crescimento institucional" variou para cada tipo de organização ${ }^{11}$.

Lamentavelmente, isso está muito além do que o estágio atual da pesquisa nessa área permite. É possível, no entanto, dar um passo adiante e especificar melhor as matrizes organizacionais dos atuais serviços de inteligência. Para tanto, na próxima seção, serão utilizados dados referentes a diferentes países e a distintos momentos históricos para a composição de um primeiro esboço interpretativo.

\section{ORIGENS: DIPLOMACIA, GUERRA E POLICIAMENTO}

O surgimento dos sistemas nacionais de inteligência está associado, segundo Michael Herman (1996:2-35), ao lento processo de especialização e diferenciação organizacional das funções informacionais e coercitivas que faziam parte, integralmente, da diplomacia, do fazer a guerra, da manutenção da ordem interna e, mais tarde, também do policiamento na ordem moderna. Embora as primeiras organizações surgidas em cada uma dessas matrizes tenham desaparecido e as organizações atuais possuam uma escala de operações muito maior e mais complexa do que seus precedentes históricos, pode-se obter uma visão mais concreta da dupla natureza dos serviços de inteligência analisando-se cada uma dessas três matrizes organizacionais separadamente $^{12}$.

\section{Diplomacia e Inteligência Externa}

As relações diplomáticas permanentes que se tornaram comuns na Europa entre os séculos XVI e XVII, seguindo os passos da diplomacia renascentista, serviam tanto para a representação e a negociação dos interesses coletivos das unidades políticas quanto para a obtenção e comunicação de informações ${ }^{13}$. Aliás, foi somente em meados do século XVII que as três grandes potências européias da época (Inglaterra, França e Espanha) passaram a contar com arquivos diplomáticos organizados e utilizáveis para a recuperação de informações. As 
chancelarias também começaram a coletar novas informações, tanto ostensivamente como por meios encobertos.

No caso da Inglaterra, desde que Francis Walsingham tornou-se secretário de Estado de Elizabeth I em 1573, uma das funções mais importantes da Secretaria passou a ser o controle do que era chamado então de "the intelligence". O termo não significava apenas a provisão de informações extraordinárias sobre potências inimigas (especialmente sobre a frota espanhola antes de 1587) ou conspiradores internos (como os jesuítas e outros perseguidos com base no Treason Act de 1351), mas incluía também um suprimento regular de notícias internacionais e informações sobre o mundo ${ }^{14}$.

A maior parte dessas notícias era relativamente rotineira e não provinha de fontes secretas, embora isto deva ser relativizado, porque a própria distinção moderna entre domínio público e secreto não era clara naquele período. Até o surgimento dos jornais privados e o advento da liberdade de imprensa, os governos tendiam a ver toda informação sobre a população, a administração e os recursos do país como propriedade do rei, portanto secreta em alguma extensão ${ }^{15}$. Assim, os governos consideravam aceitável que seus embaixadores residentes em outros países tentassem obter aquelas informações por todos os meios disponíveis, inclusive recrutando espiões e interceptando clandestinamente mensagens de terceiros. Isso não foi alterado substancialmente sequer pelas novas práticas introduzidas depois da Paz de Westfália (1648). Na Inglaterra, as redes de agentes controladas quase pessoalmente pelo secretário de Estado continuaram a existir muito depois da morte de Sir Walsingham em 1590, tanto sob Cromwell como depois da restauração e da Revolução Gloriosa (1688), indicando que as atividades de inteligência eram tidas como necessárias à afirmação da autoridade do Estado nacional emergente e não meramente um capricho dos diferentes regimes políticos.

O aumento do tráfego diplomático, juntamente com o surgimento de serviços de correio na Europa moderna, demandaram um uso regular de cifras e códigos secretos de escrita (criptografia) para proteger as comunicações entre as chancelarias e suas embaixadas. Com isso, surgiram as primeiras organizações especializadas na interceptação clandestina e decodificação (criptologia) de mensagens, as chamadas "câmaras negras" (black chambers) ${ }^{16}$. Não obstante a notável continuidade histórica do cabinet noir francês, instituído por Henrique IV em 


\section{Marco Cepik}

1590 e famoso sob a direção do cardeal Richelieu no século seguinte, o exemplo inglês é mais típico inclusive pela descontinuidade entre as primeiras organizações e os serviços de inteligência atuais.

Em 1782, a separação das funções do secretário de Estado em dois escritórios distintos, o Foreign Office para os assuntos exteriores e o Home Office para os assuntos internos da Inglaterra, refletiu-se na divisão da atividade de inteligência ao longo das mesmas linhas interna e externa. Além disso, a própria coleta de informações sobre o exterior foi repartida em duas atividades distintas, a espionagem e a criptologia, sendo que o escritório secreto de criptologia foi transferido para o serviço postal inglês, onde os despachos diplomáticos e a correspondência considerada sensível continuaram regularmente sendo interceptados, copiados, reenviados e, quando necessário e possível, decodificados até 1844 . No final do século XVIII, o Parlamento britânico passou a votar uma verba secreta anual para financiar as operações de inteligência do Foreign Office e do Secret Office and Deciphering Branch (criptologia), dinheiro empregado também para comprar apoios políticos e militares no Continente (ver Kennedy, 1989, cap. 3). Aquele Secret Service Fund foi administrado pelo War Office até o começo do século XX, quando se formaram as atuais agências britânicas de inteligência.

Desdobramentos organizacionais desse tipo continuaram a ocorrer mais tarde e, de modo geral, as funções secretas de negociação, conspiração, inteligência e espionagem exercidas desde a época elizabethana pela diplomacia britânica, assim como pela francesa, austríaca, piemontesa, prussiana ou russa, estão na origem dos serviços especializados formados entre a segunda metade do século XIX e os anos iniciais da Guerra Fria.

Há, no entanto, diferenças cruciais na escala das atividades e na dimensão das organizações. Enquanto a agência central de criptologia do governo britânico nos dias de hoje, o Government Communications Headquarters - GCHQ, empregava 6.076 funcionários e tinha um orçamento de centenas de milhões de libras esterlinas em 1995, no seu auge, no século XVIII, o Secret Office and Deciphering Branch possuía um total de nove empregados e só passou a ter um modesto orçamento regular a partir de 1782. Além da escala comparativamente diminuta das operações de coleta, a análise e validação das informações obtidas eram feitas de forma completamente ad hoc. Não havia staffs 
separados e especializados de analistas, pois a própria atividade de inteligência não se separava da formulação e implementação de políticas e linhas de ação. Para acompanhar a formulação sintética de Michael Herman (1996:13), pode-se dizer que para os reis e seus ministros a atividade de inteligência era parte das funções regulares do estadista, sendo inseparável do exercício do poder.

A separação progressiva entre as funções de inteligência e de formulação e implementação de políticas (policymaking) foi tão lenta quanto a separação entre as atividades diplomáticas legítimas e as operações secretas de influência e espionagem. Em 1939, por exemplo, o embaixador francês em Berlim ainda dispunha de fundos secretos destinados à compra de informações (Young, 1984). Em tese, porém, hoje em dia, trata-se de dois ramos separados e especializados da ação estatal no plano internacional. Dado que a maioria dos alvos dos serviços de inteligência são externos, deriva daí uma acentuada disputa burocrática pelo controle dos fluxos de informação do exterior para os governantes. É bem conhecida a rivalidade existente entre a Central Intelligence Agency - CIA e o State Department nos Estados Unidos, o que também ocorre entre o Secret Intelligence Service - SIS e o Foreign and Commonwealth Office - FCO na Grã-Bretanha ${ }^{17}$.

Atualmente, muitos países mantêm organizações de inteligência subordinadas aos seus Ministérios de Relações Exteriores para apoiar especificamente o acompanhamento de crises, negociações de acordos, tratados internacionais etc. Esse é o caso do Bureau of Intelligence and Research - INR do Departamento de Estado norte-americano, que faz parte do sistema de órgãos de inteligência do governo dos Estados Unidos, embora não realize operações próprias de coleta de informações (a não ser aquelas ostensivamente disponíveis ao público nos países com representação diplomática dos Estados Unidos). O INR recebe informações coletadas por outras agências e as analisa para o secretário de Estado. Na Inglaterra, o Departamento de Análise e Pesquisa do FCO cumpre funções semelhantes, embora não seja membro formal do sistema nacional de inteligência daquele país.

Além de ter gerado suas próprias organizações específicas de inteligência, a diplomacia moderna também esteve na origem remota de muitas das chamadas agências nacionais de coleta de inteligência externa (foreign intelligence). Nacional, nesse contexto, indica apenas que se trata de organizações que respondem diretamente ao primei- 
ro-ministro, presidente ou secretário-geral, e que prestam serviço para o governo como um todo e não somente para um ministério específico. São exemplos desse tipo de organização a CIA norte-americana e o SIS britânico, citados anteriormente, bem como a Direction Générale de la Sécurité Extérieure - DGSE francesa, o Ha-Mossad le Modiin ule-Tafkidim Meyuhadim - MOSSAD israelense, o atual Sluzhba Vnezhney Rasvedki - SVR russo, o Servizio perle Informazioni Generali e Sicurezza - SISDE italiano e, ainda, o Bundesnachrichtendienst - BND alemão. Muitos outros serviços de inteligência poderiam ser citados, mas bastam alguns exemplos de organizações mais conhecidas e até hoje atuantes ${ }^{18}$.

Os serviços de inteligência exterior são "clássicos", pois têm como característica comum o fato de serem os principais responsáveis pela espionagem propriamente dita e também pela coleta de informações a partir de fontes ostensivas fora do território nacional. Eles diferem bastante de um país para outro em termos organizacionais, na escala de operações e na composição predominantemente civil ou militar de seus oficiais de inteligência. Mas isso não impede que cada um desses serviços veja a si próprio como primus inter pares dentro do sistema de inteligência de seus respectivos países. Por outro lado, a despeito de suas raízes na diplomacia secreta presente na trajetória de qualquer Estado antigo ou moderno, há uma grande descontinuidade histórico-organizacional entre as primeiras redes modernas de agentes à maneira da Inglaterra elizabethana e os atuais serviços de inteligência exterior, que surgiram e se desenvolveram somente no século XX.

Nesse sentido, embora a primeira imagem quando se fala de serviços de inteligência remeta às organizações responsáveis por humint, tais como o SIS e o MOSSAD, na maioria dos países esse componente dos sistemas nacionais de inteligência não é o maior, o mais antigo ou o que produz maior volume de informações de valor crítico. Por exemplo, as organizações militares de inteligência surgiram já na segunda metade do século XIX, tendo se tornado muito maiores e mais numerosas do que os serviços de inteligência exterior. Essa segunda matriz de origem dos atuais serviços de inteligência será considerada a seguir.

\section{Guerra e Inteligência de Defesa}

No caso da guerra, o registro da presença de atividades de inteligência é muito mais antigo. Relatos sobre o uso de espiões militares re- 
montam ao Velho Testamento da Bíblia ${ }^{19}$, assim como figuram prescritivamente no manual de Sun Tzu sobre a arte da guerra ${ }^{20}$, o Ping-fa, escrito na China no começo do século IV a. C. Na verdade, o reconhecimento do campo de batalha e do inimigo sempre foi considerado um elemento essencial da capacidade de comando do general. Entretanto, desde a época dos speculatores utilizados pelas legiões romanas de César até os corpos de guias usados pelos franceses e britânicos durante as guerras napoleônicas, a inteligência militar foi exercitada em um contexto institucional que Martin Van Creveld (1985:17-57) chamou de a "idade da pedra do comando".

Foi somente com as transformações radicais introduzidas na área militar durante o período da Revolução Francesa e de Napoleão que começou a modificar o significado da inteligência para o comando ${ }^{21}$. $\mathrm{O}$ quartel-general móvel de Napoleão, pelo menos desde 1805, consistia de três elementos principais e independentes entre si: a Maison privada do próprio imperador, o État Majeur de l'Armée e o quartel-general administrativo. Paradoxalmente, o órgão mais importante para o comando do Grand Armée era a Maison, à qual estava subordinado um bureau de estatística encarregado da inteligência estratégica sobre os inimigos, bem como um bureau topográfico incumbido de recolher as informações das várias fontes e prepará-las, inclusive cartograficamente, para que Napoleão as estudasse diariamente. As fontes de informação eram diversas, desde mapas, jornais e livros, passando por informantes e espiões plantados em cada cidade importante, até correspondências interceptadas e decodificadas pelo cabinet noir (criado em 1590). A inteligência operacional durante as campanhas era obtida também pelas patrulhas de cavalaria das unidades e passada para o bureau topográfico através do estado-maior, que incluía em sua organização uma seção para interrogar prisioneiros, camponeses e desertores. O próprio imperador tinha uma rede pessoal de fontes de inteligência, seus officiers d'ordonnance e generais ajudantes que ele enviava em missões especiais. Entretanto, embora organizada em uma escala massiva como nunca antes havia existido, os métodos e as tecnologias de inteligência disponíveis para Napoleão permaneciam em grande medida os mesmos da Antiguidade.

Além de imperador e comandante militar, Napoleão era seu próprio oficial de inteligência. Como destaca Creveld (idem:68), essa capacidade de Napoleão para analisar e processar informações pessoalmente, eliminando muitos passos e camadas organizacionais intermediá- 


\section{Marco Cepik}

rias, ajuda a explicar a velocidade e a decisão da forma napoleônica de fazer a guerra e comandar o Grand Armée. Por outro lado, alerta Creveld, isso também poderia induzir a tomadas de decisão repentinas baseadas em desejos mais do que em análises, em segundos pensamentos ou mesmo na falta de um pensamento adequado.

Apesar desses problemas, a mudança na utilização da inteligência foi parte integrante da revolução nas estruturas de comando iniciada pelas guerras napoleônicas e que duraria praticamente até o final da I Guerra Mundial. Ao longo do século XIX, a mobilização de exércitos com milhões de soldados e a construção de grandes marinhas, as novas tecnologias de armamentos e de propulsão, o uso de ferrovias e telégrafos (mais tarde rádios), enfim, a nova escala e a complexidade da gestão do fenômeno bélico modificaram profundamente as estruturas de comando, controle, comunicações e inteligência $-\mathrm{C}^{3} \mathrm{I}$ das Forças Armadas (cf. Coakley, 1991)22.

O modelo mais influente de estruturação do comando foi o do estado-maior geral prussiano, que começou a afirmar-se a partir de $1815 \mathrm{e}$ alcançou grande prestígio internacional após as vitórias da Prússia sobre a Áustria (1866) e a França (1870). Como lembra Martin Van Creveld: "Foi somente na metade do século XIX que o tradicional coup d'oeil, com suas implicações em termos de imediata observação pessoal, deu lugar à chamada 'estimativa da situação', derivada das práticas alemãs, implicando o estudo de mapas e a produção de relatórios escritos" (1985:57).

A inteligência militar no século $X X$ reteve algo dessa nova exigência de cientificidade e abrangência destacada por Van Creveld. Em comparação com a linha evolutiva derivada da diplomacia secreta dos séculos XVI a XVIII, pode-se dizer que a inteligência militar acrescenta à conspiração e espionagem uma nova dimensão, a da coleta sistemática de informações básicas e menos perecíveis, seguida pela análise dos fatos e idéias novas tendo como pano de fundo aqueles acervos informacionais, redundando na apresentação de relatórios de inteligência orientados para tornar mais racionais e "informadas" as decisões de comando ${ }^{23}$.

No começo do século XX, a maioria dos países europeus havia adotado alguma versão de estado-maior geral que incluía esferas de responsabilidade formalmente separadas em seções (operações, plane- 
jamento, inteligência, logística, comunicações etc.). Cabe notar, entretanto, a observação de Creveld de que, mesmo no caso prussiano, na prática ainda não havia uma especialização completa de funções divididas entre as seções de operações, doutrina e inteligência. Isso teria implicado, pelo menos até a I Guerra Mundial, significativa superposição de atribuições dessas seções no estado-maior geral alemão. De modo geral, a experiência da I Guerra Mundial forçou uma maior especialização, principalmente quando às funções de inteligência exercidas pelos bureaus militares de estatística e de topografia desde a primeira metade do século XIX se somaram as novas seções de "exércitos estrangeiros" (foreign armies), responsáveis pelo estudo das Forças Armadas dos inimigos potenciais ou efetivos.

O relativo atraso da Inglaterra e dos Estados Unidos na adoção do modelo de estados-maiores gerais refletia diferenças constitucionais e políticas, mas também o tamanho bem menor de suas Forças Armadas até meados do século XIX. Isso implicou em demora na montagem de staffs e unidades militares de inteligência. No caso inglês, por exemplo, somente depois da Guerra da Criméia (1853-1856) foram enviados adidos militares permanentes para outros países para observar as Forças Armadas. Ao mesmo tempo, foi criado um Topographical and Statistical Department subordinado diretamente ao War Office. Em 1873, aquele departamento foi renomeado como Intelligence Branch, seguido do estabelecimento de um departamento separado de inteligência para o subcontinente indiano em 1878. Por sua vez, o almirantado (Admiralty) criou um comitê de inteligência em 1882, no mesmo ano em que a Marinha dos Estados Unidos fundava a mais antiga organização de inteligência ainda em atividade naquele país, o Office of Naval Intelligence - ONI. No caso britânico, em 1887 foram nomeados pela primeira vez diretores de inteligência no War Office e no Admiralty. $\mathrm{O}$ advento de um estado-maior geral após a Guerra dos Bôeres (1899-1902) amalgamou o cargo de diretor de inteligência militar - DMI com o de diretor de operações militares - DMO, em um movimento pendular que reflete a instabilidade da nova função de inteligência destacada por Creveld, um indicador de que a institucionalização dos serviços de inteligência ainda estava distante. A posição autônoma do diretor de inteligência no War Office britânico só voltou a ser restaurada em 1915 (cf. Herman, 1996:16-19). Mesmo então a separação não era completa e a inteligência de sinais (sigint) derivada da interceptação e decodificação de mensagens permaneceu 
insulada em relação a outras fontes de informação até bem depois da Batalha da Jutlândia ${ }^{24}$. As disputas pelo controle dos fluxos informacionais e a precária especialização e coordenação das equipes de analistas foram um problema para a inteligência militar até pelo menos a II Guerra Mundial, como atesta o exemplo norte-americano em Pearl Harbor $^{25}$.

Mesmo levando em conta essa separação lenta entre inteligência e as funções de planejamento e operações, as organizações permanentes e especializadas de inteligência militar tornaram-se parte estável das estruturas de comando, controle e comunicações das Forças Armadas bem antes de surgirem as organizações nacionais de inteligência externa.

Depois da II Guerra Mundial, além do staff da seção de inteligência do estado-maior geral, em cada força singular foram sendo criadas unidades especializadas ou staffs de inteligência para os níveis inferiores de comando da força. Além disso, muitos países que possuem ministérios da defesa e uma maior integração das forças armadas criaram também agências de inteligência de defesa (defense intelligence) para apoiar os estados-maiores integrados (joint) e os ministros ${ }^{26}$. São exemplos atuais dessa nova "camada" organizacional o Glavnoye Razvedyvatelonoye Upravlenie - GRU russo, a Defense Intelligence Agency DIA norte-americana, o Servizio perle Informazioni e la Sicurezza Militare - SISMI italiano, o Agaf Modiin - AMAN israelense e o Defence Intelligence Staff - DIS britânico.

À exceção do GRU, instituído entre 1918 e 1924, as demais organizações mencionadas datam do segundo pós-guerra. Cada uma dessas organizações centrais de inteligência de defesa apresenta uma escala e abrangência de capacidades operacionais nas áreas de coleta e análise de informações no exterior que é comparável com a dos serviços nacionais de inteligência exterior de seus países. Em função disso, é conhecida a rivalidade entre a DIA e a CIA, no caso dos Estados Unidos, ou entre o AMAN e o MOSSAD, no caso de Israel, para citar apenas dois exemplos. Quando se somam a essas organizações centrais de inteligência de defesa os recursos e agências de inteligência das Marinhas, Exércitos, Forças Aéreas e outras forças singulares e comandos integrados (joint commands), fica evidente que o componente militar dos sistemas nacionais de inteligência é, de longe, o maior e mais complexo do ponto de vista organizacional, correspondendo a algo 
entre $50 \%$ e $80 \%$ de todos os recursos de inteligência de qualquer país ${ }^{27}$.

Uma descrição satisfatória das relações entre esses órgãos centrais de inteligência militar e as demais organizações, centros e unidades de cada força singular em vários países exigiria um livro inteiro ${ }^{28}$. Sobre o significado da formação de subsistemas de inteligência militar para a configuração final dos sistemas nacionais e a agilidade no ciclo das atividades de inteligência, serão feitas algumas considerações adicionais na próxima seção. Antes, porém, é preciso destacar ainda uma outra matriz organizacional dos serviços de inteligência contemporâneos.

\section{Policiamento e Inteligência de Segurança}

A terceira matriz histórica dos serviços de inteligência contemporâneos distingue-se das duas anteriores por sua ênfase nas chamadas ameaças internas à ordem existente. Trata-se da inteligência de segurança (security intelligence), conhecida também como inteligência interna ou doméstica. As origens das atuais organizações de inteligência de segurança remontam ao policiamento político desenvolvido na Europa na primeira metade do século XIX, decorrente da percepção de ameaça representada por movimentos inspirados na Revolução Francesa e pelo nascente movimento operário anarquista e socialista.

As forças especializadas em manutenção da ordem interna desenvolveram técnicas e recursos de vigilância, infiltração, recrutamento de informantes e interceptação de mensagens para a repressão política dos grupos considerados subversivos. Embora o temor da revolução popular tenha diminuído um pouco depois de 1848, o processo mais geral de profissionalização das polícias e a emergência de unidades de investigação criminal continuaram ampliando as capacidades de detecção, captura, interrogação, periciamento técnico, vigilância e armazenamento de informações sobre novas áreas criminais e segmentos populacionais (Dandeker, 1990:119-133; Goldstein, 1983). A "cientificização" do combate ao crime a partir do século XIX estendeu-se ao policiamento político e à repressão contra a "subversão".

Conforme Jeffrey Richelson (1986:1-4), a primeira organização permanente voltada para a obtenção de inteligência sobre os "inimigos internos" visando à sua repressão foi a "Terceira Seção" do departa- 
mento de segurança do Estado, instituída na Rússia imperial em 1826. Os dois precedentes mais importantes da Terceira Seção foram a Oprichnina (1565-1572), a cavalaria negra instituída pelo primeiro czar de todas as Rússias, Ivan, o Terrível, bem como a organização Preobazhensky (1697-1729), criada por Pedro I para investigar, prender, interrogar sob tortura e aplicar penas contra traidores e outros suspeitos de crimes contra o czar e o Estado. Embora a repressão mais ou menos sistemática dos dissidentes e críticos seja um traço característico de todos os Estados, o policiamento político organizado foi uma especialidade russa na era moderna. Na segunda metade do século XIX, a dinastia Romanov contratou o prussiano Wilhelm Stieber para reorganizar a polícia política. Depois do atentado à bomba que matou o czar Alexandre II, em 1881, a Okhrannoye Otdyelyenye (conhecida como Okhrana) consolidou-se como uma força policial "especializada", independente tanto dos ministérios do interior e do exterior quanto dos incipientes recursos de inteligência das Forças Armadas. Considerada mais cruel do que eficiente inclusive por seus adversários bolcheviques, de qualquer modo a polícia secreta do czar tornou-se o símbolo de toda uma era. A experiência russa da Okhrana também nos ajuda a entender a persistente associação entre inteligência e repressão política ao longo do século XX.

Embora organizações como a Okhrana russa ou a Surreté Générale francesa (instaurada ainda sob Napoleão Bonaparte ${ }^{29}$ ) inicialmente não conduzissem operações de espionagem e obtenção de inteligência contra alvos estrangeiros, a busca de informações e a perseguição a adversários do regime no exílio rapidamente estenderam o policiamento político ao exterior. Em 1870, a Surreté tinha mais de sessenta agentes operando em estações em Viena, Amsterdã, Hamburgo e outras cidades européias. A primeira base permanente da Okhrana no exterior data de 1882, menos de um ano após sua reorganização (cf. Andrew, 1984; Fischer, 1997). Além de caçar revolucionários russos exilados, a Okhrana também passou a tentar monitorar as atividades de órgãos de segurança e inteligência estrangeiros, tais como a própria Sûreté, atuando em território russo.

Como resultado dessa dinâmica, no começo do século XX já havia considerável superposição de missões e alvos entre as polícias políticas e as organizações de inteligência voltadas para o exterior, que naquela época ainda eram principalmente militares. As polícias políticas controlavam redes próprias de agentes recrutados nas embaixa- 
das estrangeiras situadas nas capitais de seus países, interceptavam comunicações dos grupos dissidentes e das embaixadas estrangeiras, além de tentarem estabelecer redes de agentes e informantes em outros países ${ }^{30}$.

Principalmente depois da I Guerra Mundial e da Revolução Russa, as polícias políticas e serviços secretos de cada país passaram a vigiar regularmente as atividades dos serviços de inteligência estrangeiros dentro do território nacional. Com isso, além da inteligência de segurança (security intelligence) propriamente dita, essas organizações se especializaram também em contra-espionagem e contra-inteligência (counterintelligence). Com o processo de descolonização durante a Guerra Fria e com o terrorismo nos anos 70, certas operações de suporte à contra-insurgência, contramedidas defensivas e antiterrorismo foram acrescentadas ao leque de missões desse tipo de organização. Nas últimas duas décadas, o crime organizado, o tráfico de drogas e crimes eletrônicos (incluindo fraude financeira e lavagem de dinheiro) adquiriram tal importância na agenda de segurança de alguns países que a busca por informações extrapolou os limites da rotina da investigação criminal $^{31}$.

Essa expansão das missões ocorreu de forma mais ou menos concomitante à transformação dos antigos serviços secretos e polícias políticas em serviços de inteligência de segurança (security intelligence), principalmente nos países democráticos. Não há, entretanto, nada parecido com um modelo organizacional internacionalizado nessa área.

Em alguns países, as agências de security intelligence são separadas organizacionalmente das polícias e da inteligência externa. Atualmente, serviços como o Canadian Security Intelligence Service - CSIS, a Direction de la Surveillance du Territoire - DST francesa, o Bundesamt für Verfassungsschutz - BfV alemão e o Sherut ha'Bitachon ha'KlaliShin Bet israelense exemplificam essa separação ${ }^{32}$. Já em outros países, a inteligência interna ou de segurança é um departamento especializado das próprias forças policiais. Este é o caso dos Estados Unidos com a divisão de segurança nacional (inteligência) do Federal Bureau of Investigation - $\mathrm{FBI}^{33}$.

Na prática, porém, pode-se dizer que em todos os países as missões de inteligência de segurança, contra-inteligência e inteligência polici- 
al dificilmente estão subordinadas a uma única agência. No Japão, por exemplo, essas atividades são compartilhadas de forma tensa pela Agência de Investigação e Segurança Pública (Koan Chosa Cho) e a unidade de combate à subversão da Agência Nacional de Polícia (Keisatsu Cho $)^{34}$. Em alguns outros países ainda, a inteligência interna ou de segurança chegou mesmo a se desdobrar diretamente das Forças Armadas ${ }^{35}$.

Esse é precisamente o caso da Inglaterra. Como se sabe, a criação da polícia metropolitana de Londres, em 1829, foi o primeiro passo na lenta consolidação de uma estrutura de forças locais ao longo do século XIX na Inglaterra, onde as polícias tiveram pouca influência direta na formação do serviço de inteligência de segurança ${ }^{36}$. Segundo Michael D. Lyman (1999:63-98), embora fossem recrutados alguns informantes e a correspondência pessoal de suspeitos de subversão fosse interceptada, algum policiamento especializado contra ameaças internas só teria começado em 1883, com a criação de uma seção especial na polícia metropolitana de Londres para colher informações e reprimir os fenianos irlandeses.

Em 1909, com a criação do Secret Service Bureau subordinado ao War Office, a inteligência de segurança e a contra-espionagem passaram para a esfera da seção doméstica do bureau militar (conhecida como MI-5, ou quinta seção da inteligência militar). Em 1931, a seção de inteligência exterior (MI-6) e a seção de inteligência doméstica (MI-5) do War Office foram separadas definitivamente em duas agências independentes, respectivamente, o Secret Intelligence Service-SIS e o Security Service (que permaneceu sendo conhecido como MI-5) ${ }^{37}$. Após diversas batalhas burocráticas com a polícia metropolitana, as funções de inteligência de segurança foram inteiramente transferidas para o Security Service depois da II Guerra Mundial. Uma exceção importante foi a jurisdição sobre o combate ao Irish Republican Army IRA, que permaneceu separada em vários ramos do governo britânico. Somente em 1992 o Security Service (MI-5) passou a centralizar as operações de inteligência e repressão contra o IRA, mas mesmo assim só no restante do território britânico, pois na Irlanda do Norte o papel do MI-5 continuou secundário em relação ao do special branch do Royal Ulster Constabulary - RUC (ver, p. ex., Gill, 1994).

Refletindo o processo de expansão das missões dos serviços de inteligência interna mencionado anteriormente, em 1999, as áreas de traba- 
lho do Security Service britânico dividiam-se oficialmente em: terrorismo relacionado com a Irlanda do Norte $(30,5 \%)$, terrorismo internacional $(22,5 \%)$, contra-espionagem $(20,5 \%)$, segurança $(11,5 \%)$, crimes graves $(7 \%)$, proliferação de armas $(3,5 \%)$ e assistência a outras agências $(4,5 \%)^{38}$. Em comparação com anos anteriores, em que três quartos dos recursos do MI-5 eram dedicados ao contraterrorismo e ao IRA, a atual distribuição de prioridades enfatiza a contra-inteligência e o combate ao crime organizado. Isto resulta em parte da diminuição relativa da escala de conflitos na Irlanda do Norte e também da percepção britânica de que o país segue sendo alvo de operações de espionagem internacional.

O caso inglês apresenta, pois, diferenças de desenho organizacional e de timing em relação aos casos francês e russo, em que os serviços de inteligência de segurança surgiram das polícias secretas atuantes já na primeira metade do século XIX, mas também é diferente do caso norte-americano, em que a própria polícia federal (FBI) é a principal agência de inteligência de segurança, ou ainda em relação ao caso canadense, em que um serviço de inteligência de segurança (CSIS) foi criado apenas em 1984 como resposta às investigações parlamentares sobre violações de direitos humanos cometidas pela divisão de segurança da Royal Canadian Mounted Police - RCMP ${ }^{39}$.

Talvez mais importante do que a especificidade do caso inglês seja o que ele tem em comum com os demais países em qualquer uma das três matrizes: a dificuldade de estabelecer fronteiras organizacionais bem definidas nas diferentes áreas e missões de inteligência. Na próxima seção, poder-se-á ver como isso está relacionado com a própria lógica de expansão recente dos serviços de inteligência e seus reflexos na configuração de diferentes tipos de sistemas nacionais.

\section{LÓGICA DE EXPANSÃO DOS SISTEMAS DE INTELIGÊNCIA}

Três tipos diferentes de organizações especializadas foram destacados na seção anterior: inteligência externa (foreign intelligence), inteligência militar (military intelligence) e inteligência interna. Além desses componentes organizacionais principais, presentes na maioria dos Estados, a formação de sistemas nacionais de inteligência está associada a dois movimentos adicionais de expansão organizacional e especialização funcional que vêm ocorrendo nas últimas décadas: um movimento de expansão vertical envolvendo a formação de subsiste- 
mas de inteligência policial e de inteligência militar; um movimento de expansão horizontal, com o surgimento de novas agências especializadas em diferentes disciplinas de coleta e análise ao longo do continuum operacional que caracteriza o ciclo da inteligência.

A expansão das missões dos serviços de inteligência interna, inicialmente restritas ao policiamento político de dissidentes e mais tarde abarcando a contra-inteligência, o contraterrorismo e inteligência sobre o crime organizado, acabou por aproximar esses serviços das unidades investigativas das polícias encarregadas de dinâmicas criminais mais complexas, tais como o narcotráfico, fraudes financeiras, lavagem de dinheiro e outros crimes eletrônicos (cybercrimes). Em muitas polícias existem agora unidades especializadas em inteligência sobre crime, utilizando informações coletadas de fontes diversas (inclusive imint e sigint) e métodos analíticos mais sofisticados (principalmente nas áreas de georreferenciamento de dinâmicas criminosas e de visualização de relacionamentos entre criminosos). Essa expansão vertical do uso de métodos e técnicas de inteligência para a base dos sistemas policiais, em combinação com uma maior integração e busca de sinergia entre as unidades de inteligência policial e as agências nacionais de inteligência de segurança, pode ser apontada como uma tendência na direção da formação de subsistemas de inteligência de segurança.

Um fenômeno semelhante de verticalização de capacidades nacionais ocorre na área de inteligência militar. Como foi mencionado na seção anterior, nos países onde foram criados comandos integrados (joint commands) e estruturas mais desenvolvidas de suporte nos ministérios de defesa, isso tendeu a ser acompanhado da criação de agências centrais de inteligência de defesa. Em alguns casos, a instituição dessas agências não significou que o Exército, a Marinha e a Aeronáutica abrissem mão de suas próprias organizações centralizadas responsáveis pela produção de inteligência para o estado-maior e o comandante de cada força. Além das organizações centrais de inteligência em cada força, compõem ainda o subsistema de inteligência militar as unidades militares especializadas, desde seções menores até batalhões ou mesmo brigadas no caso da força terrestre, esquadrões e alas no caso da Força Aérea, que atendem às necessidades de inteligência dos níveis inferiores de comando. 
Além das três matrizes históricas e da formação de subsistemas de inteligência policial e militar, os sistemas nacionais de inteligência atualmente existentes resultam também de uma expansão "horizontal", decorrente de especializações funcionais crescentes e, no limite, da separação organizacional ao longo do continuum coleta-análise de informações.

A especialização principal se deu nas técnicas e tecnologias adequadas às diversas fontes de informação. Novos métodos de coleta e processamento, novas plataformas e sistemas modificaram as estruturas de custos e a composição da força de trabalho envolvida na atividade de inteligência. No que hoje se denomina coleta de informações de fontes singulares (single-source collection), por exemplo, existem atualmente órgãos ou unidades especializadas em obter informações a partir de fontes humanas (humint), da interceptação e decodificação de comunicações e sinais eletromagnéticos (sigint), da produção e processamento de imagens fotográficas ou multiespectrais (imint), da mensuração de assinaturas e outras características técnicas (masint), bem como da coleta de fontes ostensivas como jornais, televisão, internet e livros (osint). No subsistema de inteligência de segurança mencionado anteriormente, há organizações especializadas em contra-inteligência, em medidas defensivas de segurança, em inteligência interna e inteligência policial. Finalmente, uma vez traçada a linha burocrática, orçamentária e legal que estabelece quais órgãos governamentais fazem parte oficialmente dos sistemas nacionais de inteligência, é preciso levar em conta também as agências situadas na periferia dos subsistemas de inteligência e segurança militar e policial, ou mesmo os recursos temporariamente alocados sob controle operacional das agências, por exemplo, adidos militares, laboratórios de análise, contatos diplomáticos, aviões e navios em missões de coleta de informações etc.

Em razão do grande volume de informações coletadas por plataformas tecnológicas e organizações diversas, a produção de inteligência "finalizada" sobre um alvo ou tema passou a ser um problema crescente e levou à criação, em alguns países, de organizações dedicadas apenas à análise e avaliação (all-sources analysis and assessments) das informações obtidas de fontes diversas por organizações especializadas em cada tipo de fonte ou "disciplina" da área de coleta. 
O duplo movimento de expansão vertical e horizontal dos serviços de inteligência gerou demandas gerenciais e de coordenação impensáveis mesmo durante a II Guerra Mundial e boa parte do período da Guerra Fria. Obviamente, o grau de complexidade organizacional de cada sistema nacional de inteligência varia muito, indo desde sistemas com dezenas de agências, como os Estados Unidos e a Rússia, até países como Canadá e Itália, que têm apenas duas agências principais de inteligência e segurança. Entretanto, a própria idéia de que os recursos e capacidades de inteligência de um país formem "sistemas" implica a suposição de que são gerenciados de forma mais ou menos integrada. Uma camada organizacional bastante recente no processo de "crescimento institucional" dos sistemas de inteligência são as instâncias de coordenação, gestão de recursos e supervisão das políticas nacionais para o setor. A justificativa principal para incluir essas instâncias de coordenação em um tipo ideal de sistema nacional de inteligência não é simplesmente o fato de elas existirem em Londres ou Washington, mas sim a percepção de que tendem a exercer um papel crescente também em outros países ${ }^{40}$.

Até aqui, tratou-se de descrever a lógica de expansão da atividade moderna de inteligência desde suas matrizes na diplomacia, no fazer a guerra e no policiamento até a formação de sistemas nacionais de inteligência mais ou menos complexos. No restante desta seção, serão apresentadas duas direções possíveis para uma futura explicação mais completa das causas dessa expansão.

A primeira abordagem relaciona o desenvolvimento das organizações de inteligência com o fortalecimento mais geral das capacidades institucionais do Estado, sustentando basicamente que uma "oferta" maior de serviços de inteligência depende basicamente da maior ou menor disponibilidade de recursos em cada país. A segunda abordagem vincula o surgimento e o desenvolvimento das organizações de inteligência com os atributos específicos das organizações de segurança nacional em regimes democráticos, que seriam bastante diferentes das demais burocracias governamentais voltadas para assuntos internos dos países.

Bem mais sofisticada que a afirmação grosseira do parágrafo anterior, a tese de David Bayley (1975:349-351) sobre a formação dos sistemas nacionais de polícia exemplifica bem esse tipo de abordagem. Por sistemas nacionais de polícia, o autor entende diferentes arranjos insti- 
tucionais para o provimento de ordem pública, a garantia da observância às leis e a proteção da vida e do patrimônio da população. Assumindo como premissa que cada caso nacional é único, Bayley analisa através de estudo histórico-comparativo quais seriam as variáveis mais importantes na explicação dos atributos de cada sistema policial e também na explicação de por que as características atuais (em 1975) mais importantes dos sistemas nacionais de polícia emergiram em determinados períodos históricos relativamente bem determinados na Inglaterra (1829-1889), França (1667-1700), Alemanha (1742-1871) e Itália (1815-1870) ${ }^{41}$.

As sete variáveis independentes analisadas por Bayley foram o papel do crescimento populacional, sua distribuição ao longo do continuum rural-urbano, a extensão da criminalidade e da insegurança entre a população, a revolução industrial e/ou outras transformações sociais ou econômicas desse porte, a ocorrência de revoluções e/ou outras transformações políticas desse porte, a presença de ameaças externas ou a ocorrência de guerras e mobilizações militares e, finalmente, o impacto de uma ideologia qualquer (absolutismo, liberalismo, nacionalismo, socialismo etc.).

Segundo esse autor, as características bastante diferenciadas dos sistemas policiais na Inglaterra, França, Alemanha e Itália não foram determinadas pelo crescimento populacional, grau de urbanização, taxas agregadas de criminalidade, ritmos de industrialização ou por alguma ideologia específica. As variáveis mais importantes teriam sido institucionais e políticas, desde a erosão das bases comunitárias da autoridade até as preferências dos atores mais poderosos em relação às demandas por lei e ordem, passando pela maior ou menor resistência popular ao envolvimento do governo e pela transformação interna na organização do Estado. De todas essas, a associação mais clara é aquela existente entre a expansão da capacidade do Estado e a emergência de sistemas nacionais de polícia. As mudanças do Estado a que Bayley se refere estão relacionadas com a diminuição dos custos de extração de recursos da sociedade e com o aumento geral dos níveis de produção administrativa (outputs) e consolidação da autoridade política, o que teria permitido um aumento no nível de "oferta" de serviços policiais e o amadurecimento, entre 1660 e 1890, de sistemas nacionais de polícia na Europa ${ }^{42}$. 
A ênfase excessiva nos recursos disponíveis e na evolução funcional dos sistemas policiais deixa muitas variáveis relevantes de lado (as preferências dos atores e as diferenças de desempenho institucional, por exemplo), mas a partir desse tipo de ênfase pode-se dizer, no mínimo, que a formação recente de complexos (e caros) sistemas nacionais de inteligência também correspondeu a um período de expansão geral das capacidades estatais nas últimas décadas.

Um indicador grosseiro dessa expansão é o crescimento do gasto público como parcela do Produto Interno Bruto - PIB, seja do gasto público total ou, o que no caso é mais significativo, do gasto dos governos centrais. Segundo o World Development Report publicado pelo Banco Mundial em 1997, no período entre 1960 e 1995, o gasto governamental total nos países da Organização de Cooperação e de Desenvolvimento Econômicos - OCDE subiu, em média, de um patamar inferior a $20 \%$ para quase $50 \%$ do PIB. Em 1994, somente o gasto dos governos centrais representava, em média, mais de $35 \%$ do PIB nos países da OCDE. No caso dos Estados Unidos, até a década de 1930, o gasto federal manteve-se em um patamar de aproximadamente $4 \%$ do Produto Nacional Bruto - PNB, enquanto em 1995 ele já representava 22,1\% deste. Em 1997, para um PIB de US\$ 8,11 trilhões, foram realizados naquele país gastos federais de US $\$ 1,60$ trilhão em valores correntes. Mais de $55 \%$ desses gastos foram feitos com serviços sociais (previdência, saúde, educação, habitação, serviços comunitários e bem-estar social), enquanto os gastos militares representaram cerca de $17 \%$ dos gastos federais totais (ou US\$ 258,3 bilhões). A curva de gastos sociais ultrapassou a curva de gastos militares nos Estados Unidos somente no final da década de 1960, e o crescimento médio dos gastos militares entre 1960 e 2000, já ajustada a inflação, manteve-se positivo apesar do declínio relativo após o fim da Guerra Fria ${ }^{43}$.

Por sua vez, a curva de gastos com inteligência acompanhou a evolução dos orçamentos militares depois da II Guerra Mundial. Não há relação direta conhecida entre o PIB de um país e seus gastos com inteligência, mas parece haver alguma razão entre gastos com defesa e gastos com inteligência, embora essa proporção também varie significativamente. Como não há dados confiáveis sobre orçamentos de inteligência em nenhum país do mundo - antes de tudo porque esses gastos são secretos e mesmo nos casos em que o volume total de gastos é conhecido -, as proporções alocadas para cada tipo de atividade e de 
organização são apenas estimadas por observadores externos aos governos.

No caso dos Estados Unidos e da União Soviética/Rússia, os gastos com inteligência chegaram a cerca de $10 \%$ dos gastos totais com defesa na década de 80, recuando um pouco ao longo dos anos 90. Michael Herman (1996:37) estima que os gastos com inteligência nos países da Europa Ocidental oscilem entre 3\% e 5\% do total de gastos militares. Simplesmente, não existem tais estimativas sobre os gastos consolidados com inteligência nos países mais industrializados do Terceiro Mundo ou da Europa Oriental. Com todas essas restrições, assume-se aqui, em caráter provisório, um gasto nacional médio com atividades de inteligência em torno de $5 \%$ dos gastos nacionais com defesa. A diferença dos Estados Unidos e da Rússia em relação a todos os demais países deve-se à sua condição de superpotências durante a Guerra Fria e ao custo de desenvolvimento e manutenção de suas frotas de satélites espiões.

Como regra geral, pode-se concordar com Michael Herman (idem:38-40) quando ele diz que a maior parte dos investimentos e do custeio na área de inteligência vai para as agências de coleta, enquanto análise e disseminação tendem a ser itens de despesa relativamente menores. Nos anos 90, a diminuição dos orçamentos de inteligência foi significativamente menor do que a diminuição dos orçamentos de defesa, tanto nos países da Organização do Tratado do Atlântico Norte-OTAN como nos antigos membros do Pacto de Varsóvia. Tampouco há indicações de que os gastos com inteligência tenham diminuído em qualquer país importante da Ásia, América Latina ou da vasta região que vai do norte da África até a Ásia Central.

A segunda abordagem relevante para explicar a formação dos sistemas nacionais de inteligência é uma versão modificada do novo institucionalismo, desenvolvida por Amy Zegart (1999) ao analisar o surgimento e a evolução de três agências de segurança nacional dos Estados Unidos: o National Security Council - NSC, o Joint Chiefs of StaffJCS e a Central Intelligence Agency - CIA. Segundo Zegart, o mesmo conjunto de premissas neo-institucionalistas sobre a importância das regras do jogo, da racionalidade e dilemas de ação coletiva, dos custos de transação e da natureza dos atores conduz a conclusões diferentes quando se trata de analisar agências de segurança nacional em contextos democráticos ${ }^{44}$. 
Para diferenciar as agências governamentais internas (de regulação e/ou prestação de serviços) das agências de segurança nacional, a autora considera quatro variáveis fundamentais: 1) densidade do ambiente formado pelos grupos de interesse na área de atuação de cada agência; 2) disponibilidade de informações sobre as atividades de cada agência; 3) autoridade do Legislativo ou do Executivo para o estabelecimento de diretrizes; 4) grau de interdependência burocrática e clareza jurisdicional. Com base em evidências empíricas e em um exercício taxonômico competente, Zegart estabelece uma dicotomia baseada em dois tipos opostos de agências governamentais ${ }^{45}$.

Em um extremo estariam as agências governamentais que atuam em áreas de políticas públicas regulatórias e distributivas. O meio ambiente social dessas áreas de políticas públicas é caracterizado por um grande número de grupos de interesse, poderosos e consolidados, os quais se encarregam de fornecer incentivos e sanções aos parlamentares para que eles se envolvam nas disputas sobre a estrutura e a atuação das agências de um dado setor. A disponibilidade de informações sobre as atividades da agência é alta e os obstáculos para a obtenção dessas informações são de tipo administrativo. Para a terceira variável, Zegart destaca então o papel central do Congresso nas decisões sobre a criação, o desenho organizacional e o volume de serviços (outputs) das agências governamentais domésticas. A quarta variável é a mais problemática. Segundo a autora, agências governamentais voltadas para o público nacional apresentam uma clara delimitação de funções (saúde, educação, transportes etc.) e têm grande independência operacional umas das outras.

No outro extremo estariam as agências de segurança nacional, caracterizadas em primeiro lugar pela fraca presença de grupos de interesse em seu ambiente de atuação. Mesmo nas áreas em que existem tais grupos (lobby de fabricantes privados de armamentos ou grupos de imigrantes, por exemplo), eles são relativamente menos numerosos, menos poderosos, estando orientados para resultados políticos específicos (e.g., obter um dado contrato para desenvolver um novo sistema de armas) e não para influenciar o desenho organizacional de uma agência ou o nível geral de gastos orçamentários de um setor ${ }^{46}$. Como muitas das atividades das agências de segurança nacional são conduzidas em segredo, existem barreiras legais e procedimentais para o acesso público às informações relevantes. Com custos de obtenção de informações mais altos e um ambiente rarefeito de grupos de interes- 
se, há poucos incentivos positivos para os parlamentares participarem ativamente das disputas sobre a organização ou as ênfases operacionais das agências de segurança nacional. Finalmente, em relação ao grau de interdependência burocrática, ele seria bem maior na área de segurança nacional por causa da justaposição de temas e funções que impedem uma clara delimitação jurisdicional entre as diferentes agências do setor.

A partir desta descrição de características específicas das agências de segurança nacional, Amy Zegart faz três proposições que poderiam ser testadas mediante pesquisas adicionais: 1) ao contrário do que ocorre com outros setores governamentais, cuja criação é fortemente influenciada pelos grupos de interesse e pelo Congresso, no caso das de segurança nacional, a decisão de criar uma nova agência, assim como as escolhas de seu desenho organizacional e de suas regras de funcionamento, é fortemente concentrada no Poder Executivo; 2) em conseqüência do elevado grau de interdependência burocrática e da precária delimitação de jurisdições, as agências de segurança nacional que já existem lutam entre si e com as equipes de assessores presidenciais para influenciar a definição presidencial sobre as missões, recursos e o desenho organizacional do novo órgão. A configuração final das novas organizações que estão sendo criadas depende dos resultados desses embates; 3) além de se envolver pouco nas disputas em torno da fundação de novas agências de segurança nacional, os parlamentares e o Congresso também procuram evitar o envolvimento em atividades de supervisão sobre as atividades dessas organizações, pois lhes faltam os instrumentos e os incentivos para isso.

Deixando de lado, por enquanto, as implicações dessa terceira proposição para a discussão sobre os mecanismos de controle externo de agências de segurança nacional e sobre os impactos da instituição do segredo governamental no desenvolvimento dos serviços de inteligência, note-se que até aqui Zegart fala de agências de segurança nacional sem levar em conta as dessemelhanças entre as próprias organizações desse tipo. Ao estudar os diferentes padrões de evolução das três agências na segunda metade do século XX (NSC para policymaking, JCS para comando das forças armadas e CIA para inteligência externa), Zegart conclui que três fatores, em ordem decrescente de importância, determinariam o desenho inicial e o desenvolvimento posterior de organizações na área de segurança nacional: 1) as escolhas sobre desenho organizacional e regras de funcionamento feitas 
na época de criação da agência; 2) os interesses, opiniões e linhas de ação dos atores relevantes, que mudam ao longo do tempo através das próprias interações; 3) os eventos externos que, dependendo da intensidade e do timing, podem forçar a mudança organizacional sem que os atores tenham controle sobre as variáveis ambientais ${ }^{47}$.

Quando contrastado com a abordagem histórico-estrutural de Bayley, o modelo institucional das "Agências de Segurança Nacional" de Zegart adiciona à explicação sobre a expansão dos sistemas de inteligência as escolhas dos atores relevantes (grupos de interesse, legisladores, burocracias e governantes) e as condições de incerteza em que essas escolhas são feitas, que forçam cada ator a adaptar suas preferências aos constrangimentos impostos pelos demais atores e pelo ambiente. No caso dos serviços de inteligência e de segurança, seria preciso incorporar ao modelo as próprias dinâmicas operacionais que caracterizam a atividade de inteligência, tais como coleta, análise, disseminação e contra-inteligência. Como se trata da componente informacional de um conflito em que um ator tenta dobrar a vontade de outro, o surgimento e o padrão evolutivo de sistemas de inteligência também refletem essas interações adversariais com as organizações similares de outros governos ou mesmo de atores não-estatais.

Em síntese, os serviços de inteligência e de segurança foram criados e se desenvolveram porque os governantes pretendiam resolver certos problemas informacionais associados ao provimento de defesa nacional e ordem pública, mas em cada país e em cada área de especialização funcional a disponibilidade de recursos variou, a competição interburocrática por jurisdição foi mais ou menos aguda e a capacidade de um serviço de inteligência impor parâmetros às dinâmicas conflitivas entre organizações similares subordinadas a diferentes governos foi decisiva para a configuração final de cada sistema nacional.

Para um exemplo das possíveis configurações organizacionais dos sistemas nacionais de inteligência, na próxima seção serão mencionadas muito brevemente as principais agências norte-americanas e britânicas de inteligência.

\section{ORGANIZAÇÃO DOS SISTEMAS NACIONAIS DE INTELIGÊNCIA}

Nas últimas três ou quatro décadas, formaram-se sistemas governamentais de inteligência nos países mais importantes do mundo. Dota- 
dos de maior ou menor complexidade estrutural quando considerados de forma concreta, o desenho organizacional ideal-típico de tais sistemas envolve os seguintes componentes: alguma instância central de coordenação, uma ou mais agências principais de coleta de informações (normalmente imagens e sinais estão separados de humint e fontes ostensivas), alguma instância central de análise, unidades departamentais de análise com laços mais ou menos definidos com as organizações centrais de coleta de inteligência, poderosos subsistemas de inteligência de defesa e de segurança, algum órgão de formação e treinamento e, mais recentemente, órgãos mais ou menos colegiados para coordenação e instâncias de supervisão externa, seja no próprio Poder Executivo, no Legislativo ou, mais raramente, no Judiciário.

Utilizando algumas variáveis muito genéricas, tais como o grau de centralização da autoridade sobre as unidades do sistema, o grau de integração analítica da inteligência disseminada para os usuários, a maior ou menor separação entre as funções de inteligência e de policymaking, além da efetividade dos mecanismos de accountability no Poder Executivo e no Legislativo, seria o caso de fazer comparações internacionais mais amplas para se tentar obter uma posição relativa dos casos analisados entre si e em relação ao desenho organizacional ideal-típico. Infelizmente, esse é um desafio que está além dos limites deste trabalho ${ }^{48}$.

Apenas como indicação polêmica para tratamento posterior, parece-me que há pelo menos três tipos básicos de sistemas nacionais de inteligência:

1) um modelo "anglo-saxão" caracterizado por alta centralização da autoridade sobre as unidades do sistema, alto grau de integração analítica, média separação entre inteligência e política, além de média efetividade dos mecanismos de accountability e supervisão. Nesse modelo poderiam ser incluídos os sistemas nacionais de inteligência e segurança de países como Estados Unidos, Grã-Bretanha, Canadá, Austrália, Nova Zelândia e, com reservas, Índia e África do Sul;

2) um modelo "europeu continental" caracterizado por média centralização da autoridade sobre as unidades do sistema, média integração analítica dos produtos de intel, alto envolvimento da atividade de inteligência com as instâncias de policymaking e, finalmente, uma bai- 
xa efetividade dos mecanismos de accountability e supervisão (oversight). Nesse modelo poderiam ser incluídos os sistemas nacionais de inteligência e segurança de países como França, Alemanha, Rússia, Polônia, Itália e, com reservas, Brasil e Argentina;

3) um modelo "asiático" caracterizado por baixa centralização da autoridade sobre as unidades do sistema, alta integração analítica dos produtos de intel, médio envolvimento da atividade de inteligência com as instâncias de policymaking e, de forma ainda mais pronunciada do que no tipo "europeu continental", uma baixa efetividade dos mecanismos de accountability e supervisão. Nesse modelo poderiam ser incluídos os sistemas nacionais de inteligência e segurança de países como China, Japão, Coréia do Sul, Taiwan, Coréia do Norte e, com reservas, Indonésia e Vietnã.

Obviamente, há uma grande dose de arbitrariedade e impropriedade nessa caracterização grosseira. Repito aqui as ressalvas que fiz em nota à introdução deste artigo: a forma mais corriqueira de classificação encontrada na literatura ainda consiste na dicotomia entre um modelo descentralizado com supervisão congressual (Estados Unidos) e um modelo centralizado sem controles públicos (União Soviética). Dada a evidente função ideológica dessa dicotomia, a classificação aqui proposta parece-me claramente superior. Uma taxonomia mais refinada foi utilizada por Michael Herman (1996:4), na qual o autor inglês elabora um tipo ideal a partir da abstração de traços organizacionais e operacionais observados na experiência anglo-saxã, para em seguida analisar como as regularidades se aplicam aos diversos sistemas nacionais a partir de círculos concêntricos: mais intensamente no núcleo anglo-saxão, medianamente no caso da Europa Ocidental e Israel e de forma bastante fraca no caso dos países comunistas e ex-comunistas. Embora o trabalho de Herman tenha o mérito de ser a melhor obra disponível sobre problemas teóricos na área de inteligência, seu teste dos "círculos concêntricos" não chega a ser realizado. Tampouco há aqui qualquer teste efetivo da classificação triádica (anglo-saxão, europeu continental e asiático), mas prefiro esta pois a formulação de Herman parece ser um refinamento que não rompe no essencial com a dicotomia liberal da Guerra Fria.

Particularmente problemático na classificação aqui proposta é sua dificuldade em livrar-se da referência geográfica que tende a ser bastante enganadora: o Paquistão e a Índia ficam na Ásia, mas seus apa- 
ratos de inteligência são bastante diferentes entre si. Além disso, o Paquistão é o principal aliado dos Estados Unidos na Ásia Central e no subcontinente indiano, mas é a Índia que adota mais claramente o modelo anglo-saxão em seu sistema de inteligência. O caso de Israel, caracterizado por baixa centralização da autoridade sobre as unidades do sistema, baixa integração analítica dos produtos de inteligência das várias agências, baixo envolvimento da atividade de intel com as instâncias de policymaking, alta responsividade das unidades do sistema aos governantes e média efetividade dos mecanismos de accountability e controle externo, é inclassificável nos três modelos disponíveis. Da mesma forma, uma virtual categoria de "outros" incluiria dezenas de países do Magrebe, do Oriente Médio, latino-americanos, africanos, asiáticos e da Europa Oriental. Enfim, há uma enorme tarefa de pesquisa pela frente nessa área para quem puder realizar estudos comparativos adicionais.

Mesmo com essas evidentes dificuldades, adoto provisoriamente a classificação triádica a partir da constatação preliminar de que a estrutura organizacional e os procedimentos operacionais dos serviços de inteligência japoneses e chineses se parecem mais entre si do que o sistema japonês se parece com o anglo-americano ou que o sistema chinês se parece com o soviético-russo. De todo modo, tanto em termos de capacidades militares quanto em relação aos recursos de inteligência há que se observar a enorme disparidade entre os casos norte-americano e russo e todos os demais sistemas nacionais de inteligência ${ }^{49}$.

\section{A AGILIDADE COMO DILEMA}

Em muitos países democráticos, os gastos públicos com os serviços de inteligência atualmente superam os gastos com representação diplomática. Por outro lado, os gastos com policiamento, defesa nacional ou ajuda internacional são bastante superiores aos gastos com inteligência. Isso indica que a inteligência segue sendo uma atividade "subsidiária". Ainda assim, o peso institucional desses sistemas nos arranjos de política externa, defesa nacional e provimento de ordem pública não pode mais ser ignorado (Herman, 1996:341-361).

Como foi discutido aqui, as características organizacionais dos sistemas de inteligência resultam de processos específicos de construção de soluções para os desafios da área de segurança nacional. As políti- 
cas públicas nesse domínio têm caráter menos distributivo do que em outras esferas de atuação de burocracias governamentais, e os issues principais dizem respeito, em tese, a bens públicos. Os grupos de interesse na sociedade são mais recentes e relativamente mais fracos do que em outros setores (como negócios ou habitação, por exemplo). A informação sobre a atuação das agências governamentais de segurança nacional é menos disseminada em função das restrições de segurança e segredo. Além disso, trata-se de um setor em que historicamente predomina o Poder Executivo, com um envolvimento mais baixo e menos ativista do Poder Legislativo. Finalmente, as áreas de jurisdição e os temas de segurança nacional são inter-relacionados e as burocracias envolvidas (e.g. Forças Armadas, diplomacia, polícias e órgãos de inteligência) são mutuamente dependentes, muito mais do que aquelas voltadas para temas domésticos, em que há menos justaposição de funções e atribuições. Todos esses fatores se conjugam para diminuir os incentivos que os parlamentares teriam para envolver-se no desenho e na supervisão das agências de segurança nacional.

Dadas essas especificidades das agências de segurança nacional, Amy Zegart (1999) propõe duas teses úteis para o estudo dos processos de institucionalização de serviços de inteligência. Por sua própria natureza, as burocracias da área de segurança nacional tenderiam a ser criadas por iniciativa do Poder Executivo (com um papel secundário e sempre relutante do Parlamento), seu desenho institucional refletiria as disputas entre as burocracias de segurança nacional e os interesses da equipe presidencial, com o Congresso exercendo um tipo de supervisão pouco sistemático e efetivo. Mas, se o Poder Executivo tem papel predominante na decisão de criar organizações de inteligência e se estas respondem primordialmente aos governantes e não ao público ou seus representantes parlamentares, por que o desenho organizacional e o padrão evolutivo dos sistemas de inteligência dificultam uma resposta ágil às necessidades dos governantes, policymakers e comandantes militares?

A segunda tese proposta por Zegart fornece uma primeira explicação para esse aparente paradoxo: as escolhas estruturais feitas no nascimento de um órgão de segurança nacional tenderiam a durar no tempo, e só muito lentamente essas estruturas seriam alteradas pela mudança nos interesses correntes dos principais atores (stakeholders) e por eventos externos. $\mathrm{O}$ argumento da autora, resumidamente, des- 
creve um clássico problema de relacionamento entre principal e agent: governantes eleitos (principals ou "mandantes") sofrem severos constrangimentos de tempo, conhecimento e controle sobre suas agendas políticas, e precisam realizar seus objetivos políticos contando com maiorias congressuais e apoio da opinião pública que são difíceis de ser adquiridos e que não podem ser desperdiçados com disputas sobre coisas como o melhor desenho organizacional para uma agência burocrática qualquer. Agências de segurança nacional (agents ou "agentes") têm conhecimento especializado sobre áreas de "vida e morte" para o país, têm agendas mais delimitadas do que as dos governantes e têm fortes incentivos para participar ativamente do desenho organizacional e da definição das missões prioritárias dessas agências do setor.

Em sistemas altamente complexos e com cadeias de comando cruzadas como a área de inteligência, isso impõe problemas de coordenação que limitam severamente a agilidade das respostas aos requerimentos de diferentes usuários (principals), desde os chefes de Estado e de governo até os policymakers e comandantes militares. Como o grau de interdependência burocrática na área de segurança nacional é maior, segundo Zegart, as disputas sobre jurisdição acrescentam mais uma dificuldade.

Para James Q. Wilson (1989:179-195), a busca por autonomia (entendida mais como jurisdição não disputada sobre missões específicas e menos como liberdade para agir sem controles externos) é vital para qualquer organização governamental. Isso ocorre porque ganhos de autonomia diminuem os custos da manutenção organizacional na medida em que minimizam o número de atores externos interessados e os rivais burocráticos e, também, uma vez que isso maximiza as chances de a organização desenvolver um senso de missão mais coeso. Nesse sentido, a busca por autonomia tende a ser um objetivo tão ou mais importante para os dirigentes burocráticos que a absorção de novas tarefas ou a obtenção de maiores orçamentos, justamente porque a autonomia define os custos da aquisição e de uso dos recursos ${ }^{50}$.

No caso das Forças Armadas, corpos diplomáticos, agências policiais e serviços de inteligência, é justamente a semelhança entre muitas de suas tarefas informacionais e coercitivas que tende a tornar os conflitos por autonomia particularmente agudos e persistentes ao longo do processo de institucionalização, impondo sérios custos de coordena- 


\section{Marco Cepik}

ção que limitam a capacidade de qualquer serviço de inteligência ser ágil ${ }^{51}$.

Diferentes sistemas nacionais de inteligência são mais ou menos institucionalizados, mais ou menos adaptáveis, complexos, autônomos e coerentes. Em síntese, mais ou menos ágeis. Como seus desempenhos diferenciados têm conseqüências para a segurança nacional, seria preciso discutir ainda a questão dos possíveis efeitos de uma precária supervisão congressual sobre o desempenho dos serviços de inteligência e, de modo geral, sobre o segundo desafio associado à institucionalização: o da compatibilização desses sistemas nacionais de inteligência com o princípio da transparência, mas isso será feito em outro trabalho específico sobre o tema dos controles externos.

(Recebido para publicação em janeiro de 2003)

(Versão definitiva em abril de 2003)

\section{NOTAS}

1. A crescente complexidade do Estado moderno não autoriza a conclusão despropositada de Adam Przeworski, no de resto útil Estado e Economia no Capitalismo, em que o autor afirma que o "Estado é um sistema complexo sem um centro fixo de coesão" (1995:86). O Estado não é o "centro" da sociedade como pretende a literatura estatista criticada corretamente, dentre outros, por Charles Tilly (1996) e por Przeworski (1995), mas disso não segue que esse sistema complexo não tenha um centro coesivo, um núcleo duro econômico e militar. Obviamente, o Estado não é apenas isso, como aliás se pode verificar lendo o artigo de Thomson (1995:213-233).

2. Para uma abordagem das instituições como variáveis independentes ou dependentes, ver os capítulos sobre o novo institucionalismo em Goodin e Klingemann (2000). Para uma discussão clássica sobre informações e expertise como recursos diferenciais que os burocratas possuem para influenciar a política, cf. Weber (1993, esp. caps. II, “Domínio dos Burocratas e Liderança Política”, e IV, “A Direção Burocrática na Política Externa").

3. A distinção entre organizações e instituições é fonte de confusão e polêmica na literatura especializada. Considero como instituições simplesmente aquelas organizações e/ou procedimentos formais e informais que adquiriram valor e estabilidade para os atores envolvidos nas interações (cf. Huntington, 1975:25-36; Goodin, 1996:21). Devo registrar, porém, a formulação influente de Douglass North sobre o tema. Para North, em Institutions, Institutional Change and Economic Performance, as 
organizações seriam os jogadores, enquanto as instituições seriam as regras do jogo (formais e informais). A explicação da mudança institucional seria obtida observando-se a interação ao longo do tempo entre escolhas organizacionais e diferentes conjuntos de constrangimentos institucionais (North, 1990:3-5). Por outro lado, em Peças e Engrenagens das Ciências Sociais, Jon Elster (1994:174) propõe uma distinção entre instituições e normas sociais que poderia ser complementar à de North. Para uma reavaliação do tema no contexto da sociologia, ver Prates (2000:123-146). Para uma crítica sociológica da "ambigüidade moral" envolvida na distinção entre normas, instituições e organizações, ver Perrow (1986:157-177).

4. Para uma revisão da agenda de pesquisa sobre os atributos da soberania, ver Thomson (1995). Sobre o papel da coerção e da informação na formação dos Estados nacionais, ver Giddens (1987). Na verdade, a literatura relevante sobre o Estado é imensurável, mas vale mencionar alguns outros trabalhos que oferecem sólidos pontos de partida. Sobre a evolução do Estado moderno, ver Strayer (1970) e, também, Poggi (1978). Para a relação entre capitalismo e sistema de Estados a partir do conceito de "ciclos sistêmicos de acumulação", ver Arrighi (1996). Para uma exposição didática de teorias sobre o Estado contemporâneo, ver Dunleavy e O'Leary (1987). Para um balanço das teorias marxistas do Estado, ver Jessop (1990).

5. O trabalho mais recente de Tilly (1996) mantém a ênfase explicativa "centrada no Estado" no que diz respeito à direção da causalidade, mas se fortalece analiticamente ao reintegrar de forma mais sistemática no modelo a dinâmica internacional, a economia e os resultados contingentes de conflitos sociais. Versões anteriores menos desenvolvidas do modelo encontram-se em Tilly (1985). Ver ainda o trabalho anterior já mencionado (Tilly, 1975:601-638). Para um contraponto crítico à abordagem recente de Charles Tilly, ver Spruyt (1996).

6. Ao fim e ao cabo, o argumento de Tilly também é tautológico, não obstante sua tentativa explícita de evitar isso mediante uma explicação de tipo genético-estratégico: sabemos que o Estado capitalista foi mais adaptativo e poderoso porque ele venceu os modelos concorrentes, e ele venceu os modelos de "intensa coerção" porque foi mais adaptativo e fundamentou-se em coalizões sociais mais poderosas. Para uma explicação macro-histórica sobre a dupla dinâmica formativa do mundo moderno (sistema de Estados e modo de produção capitalista), ver Arrighi (1996).

7. Robert Goodin (1996) menciona uma variante diferente de explicação evolutiva sobre a gênese e desenvolvimento de instituições. Além dos mecanismos de seleção, ele usa a idéia "hegeliana" de contradição dialética como um mecanismo que força por si mesmo, independente da vontade dos atores, a evolução. Segundo o autor, a tensão entre uma Constituição que proclama os homens livres e iguais nos Estados Unidos e a instituição da escravidão, por exemplo, geraria inevitavelmente um momentum próprio de resolução da contradição, no caso, a Guerra Civil. Na situação aqui analisada dos serviços de inteligência, a tensão entre agilidade e transparência levaria, dependendo da profundidade da contradição entre os dois valores, a uma resolução sintética pela negação e destruição de um dos dois termos. Para uma crítica dessa linha de raciocínio, ver, além do próprio Goodin, que adota a perspectiva intencional/acional como central para uma teoria do desenho institucional, o texto de Pettit (1996:54-89). 


\section{Marco Cepik}

8. Como se concebe a origem das instituições é um dos critérios utilizados para se distinguir as abordagens histórico-sociológicas da vertente da escolha racional (rational choice) no chamado novo institucionalismo. Esse critério é complementar àquele que postula o caráter endógeno ou exógeno (em relação às interações políticas...) da formação das preferências dos atores. O que o caso dos serviços de inteligência na Europa moderna parece implicar é que ambos os critérios são falhos (assim como a própria separação entre explicação sociológica e econômica...), na medida em que tais serviços responderiam, ao mesmo tempo, a imperativos estratégicos e a regras de adequação. Isso reforça os argumentos de Elinor Ostrom (1991:237-243) sobre o caráter complementar dos dois tipos de explicação. Ver, também, Ostrom (1990). A distinção entre as três (ou quatro) vertentes diferentes do novo institucionalismo é feita precariamente por Hall e Taylor (1996); ver, também, Steinmo, Thelen e Longstreth (1992). Sobre as origens do rational choice institutionalism nos estudos legislativos, ver Limongi (1994). Um comentário bastante sensato sobre as tendências analíticas recentes nos estudos legislativos é oferecido no primeiro capítulo da tese de Melo (1999). Sobre o novo institucionalismo sociológico, ver March e Olsen (1984). Um desdobramento posterior desse artigo seminal é feito em March e Olsen (1989). Ver, ainda, Powell e DiMaggio (1991). Neste último volume, particularmente útil para a modelagem de estudos sobre surgimento e transformação de instituições é o artigo de Brint e Karabel (1991).

9. A ênfase no papel exclusivamente informacional dos serviços de inteligência aparece também na ciência política de corte funcionalista. Para Almond e Powell (1966), o conhecimento e a informação permeiam todas as capacidades (capabilities) dos sistemas políticos, tais como a capacidade extrativa, a regulativa e a distributiva, além de estarem no centro de duas delas, a capacidade simbólica e a capacidade de resposta aos inputs do sistema. Também uma perspectiva "cibernética", como a de Karl Deutsch em The Nerves of Government (1966), seria a qualidade da informação que circula através dos canais de comunicações que responderia pela coesão social e, em última análise, pela possibilidade de congruência entre comandos e ações executadas: "Se a política requer uma maquinaria para garantir o cumprimento das regras e um conjunto de hábitos de conformidade, então a política é impossível sem um fluxo de informações para aqueles que se espera que obedeçam aos comandos emitidos" (Deutsch, 1966:157). Aliás, justamente por conta dessa ubiqüidade da informação na sociedade e no Estado, creio que é mais produtivo, e analiticamente mais relevante, estudar fluxos informacionais e organizações claramente delimitados, como é o caso da atividade de inteligência por exemplo, do que pretender falar de "sociedades informacionais" ou de "era da informação", que são expressões vazias de significado sociológico preciso.

10. Essa é a visão, por exemplo, de Norberto Bobbio: "não por acaso, a política dos arcana imperii caminhou simultaneamente com as teorias da razão de Estado, isto é, com as teorias segundo as quais é lícito ao Estado o que não é lícito aos cidadãos privados, ficando o Estado portanto obrigado a agir em segredo para não provocar escândalo [...]. Diferentemente da relação entre democracia e poder oligárquico, a respeito da qual a literatura é riquíssima, o tema do poder invisível foi até agora pouquíssimo explorado" (1986:28-30). Embora o ponto de Bobbio seja normativo, a suposição de base em sua crítica é que o "governo invisível" seria algo herdado historicamente e não uma construção contemporânea dos próprios regimes e atores 
políticos liberal-democráticos. Para uma reafirmação do mesmo ponto, com alguma concessão realista e pragmática que resulta inconsistente, ver Bobbio (2000).

11. A descrição da variação espaço-temporal do "crescimento institucional" é uma dimensão importante dos estudos sobre desempenho institucional, como destaca Robert Putnam no capítulo introdutório de seu impressionante livro Comunidade e Democracia: A Experiência da Itália Moderna. Segundo ele: “Nossa análise da evolução dos governos regionais em seus dois primeiros decênios inclui uma comparação 'antes e depois' que nos ajuda a avaliar o impacto da reforma institucional. Como a instituição e suas lideranças foram aprendendo e se adaptando com o passar do tempo - a 'biologia desenvolvimentista', por assim dizer, do crescimento institucional - é tema que se inclui em nossa pesquisa" (Putnam, 1996:26).

12. Esse primeiro exercício toma o roteiro de Herman (1996:2-35) e procura ampliar o uso de fontes bibliográficas que sustentem o argumento, mas é ainda nitidamente insuficiente, pois comparações internacionais sistemáticas precisariam estar baseadas em dados agregados e fontes arquivísticas para dar conseqüência ao programa de pesquisa descrito no texto já citado de Hasted (1991). Um exemplo do que deve ser feito em termos empíricos é o excelente trabalho em que David Bayley (1975) compara a emergência dos sistemas nacionais de polícia na Europa e tenta explicar os atributos dos sistemas policiais a partir da estrutura dos Estados, escrito há mais de 25 anos. Muitas das conclusões de Bayley se aplicam também ao estágio atual da pesquisa sobre serviços de inteligência.

13. Sobre a evolução das instituições diplomáticas modernas e sua relação com a espionagem, dois trabalhos principais são citados por Herman (1996:3). Para uma história mais convencional sobre as raízes da atividade de inteligência na diplomacia secreta praticada pelos soberanos modernos, ver Thompson e Padover (1965). Um trabalho mais recente sobre o significado moderno do termo inteligência nas experiências diplomáticas britânica e francesa a partir do século XVI é o de Derian (1992). Embora tenha elementos interessantes aqui e ali, de modo geral, o trabalho de Der Derian perde-se em um cipoal de análises pós-estruturalistas sobre a intertextualidade dos termos inteligência e antidiplomacia, ou sobre o poder discursivo de uma concepção "cronopolítica" e "tecnoestratégica" da guerra. Para quem se interessar por uma aplicação da aparelhagem discursiva do pós-estruturalismo à discussão sobre teoria da atividade de inteligência e vigilância, ver Derian (1993).

14. A predominância de uma abordagem histórica nos trabalhos britânicos sobre inteligência favorece que se use a Inglaterra como exemplo nesta seção. Sobre as diferentes ênfases e os respectivos problemas nos estudos sobre inteligência nos Estados Unidos e na Grã-Bretanha, ver Godson e Robertson (1987). Sobre a origem, evolução e configuração atual do sistema britânico de inteligência, ver Godson (1988). Ver, também, os capítulos sobre Inglaterra em Richelson (1988), bem como em Richelson e Ball (1985). Para a experiência da inteligência britânica na II Guerra, ver Hinsley (1993). O próprio livro de Herman (1996) traz referências importantes embora dispersas. Cf., ainda, os verbetes sobre Inglaterra e agências britânicas em Polmar e Allen (1997:181-191).

15. Sobre a gênese da esfera pública burguesa e a posterior transformação da função política da esfera pública e do princípio da publicidade, ver Habermas (1994:17-26 


\section{Marco Cepik}

e 181-211). Sobre a distinção público/secreto, um comentário adicional pode ser encontrado em Bobbio (1989:176-190).

16. A atividade de decifração é tão antiga quanto o uso da escrita para a comunicação de mensagens importantes e o uso de códigos secretos para sua redação. Segundo David Kahn (1996:93), o manual de criptologia mais antigo preservado até hoje é um trabalho árabe do século IX, descoberto em 1992. Até então, acreditava-se que o documento criptológico mais antigo fosse um outro manual árabe, escrito em 1492. O que o Estado europeu moderno talvez tenha introduzido de forma realmente original foi a organização de serviços especializados para esse fim. Ainda assim, a pequena escala das black chambers européias dos séculos XVI a XIX poderia perfeitamente ser equivalente ou até menor do que organizações semelhantes existentes na China ou nos califados árabes.

17. Na Grã-Bretanha, o Intelligence Services Act of 1994 subordinou administrativamente o SIS e o GCHQ, as duas agências de coleta de inteligência externa, ao Ministério das Relações Exteriores, o Foreign and Commonwealth Office - FCO. A subordinação direta dos órgãos de inteligência externa aos responsáveis pela tomada de decisões e implementação de políticas externas reflete a prática britânica de envolver os oficiais de inteligência e os policymakers no processo de preparação de assessments, o que no contexto norte-americano é considerado um anátema, por implicar risco de politização e enviesamento (bias) das análises. Para uma comparação direta entre as práticas britânicas e norte-americanas de produção de análises em inteligência, ver Herman (1996). Para uma utilização dessa variável ("grau de envolvimento da inteligência no processo de produção de políticas") em um modelo comparativo mais amplo, ver Johnson (1996:119-145).

18. O serviço de inteligência exterior (humint) mais eficaz do século XX foi o Primeiro Diretório do KGB soviético. O serviço mais eficiente foi o da Alemanha Oriental, o Hauptverwaltung Aufklärung - HVA. Ambos eram parte de organizações muito maiores, fundamentalmente voltadas à inteligência de segurança e ao policiamento político interno (caso dos diretórios de segurança do KGB e, no caso da Alemanha Oriental, da STASI). Sobre a inserção específica do HVA e da STASI no Ministério da Segurança do Estado da RDA, ver a autobiografia de Marcus Wolf, ex-diretor do Serviço de Inteligência Exterior da Alemanha Oriental (Wolf e McElvoy, 1997). Sobre as organizações de segurança e de inteligência da União Soviética, ver Richelson (1986) e, também, Parrish (1991). Sobre as organizações de inteligência e segurança da Rússia após o colapso do regime soviético em 1991, ver Galeotti (1996) e Knight (1996).

19. Há várias referências à espionagem nos cinco livros de Moisés do Velho Testamento, que os judeus chamam de Torah, especialmente em Números, capítulo 13, em que Deus ordena a Moisés que envie espiões à terra de Canaã, sendo cada um deles de uma das tribos de Israel, cujas funções os tornam então príncipes. A outra referência direta é no livro de Josué, capítulo 2, em que Josué envia dois espiões para fazer o reconhecimento avançado de Jericó. A estadia dos espiões de Josué na casa da prostituta Raabe, tal como aparece na Bíblia, provavelmente foi a origem do tratamento bastante comum da espionagem como a "segunda profissão mais antiga do mundo". Além da Bíblia, confrontar o verbete "biblical spies" em Polmar e Allen (1997:65-66). 
20. No último capítulo (XIII) do Ping-fa, Sun Tzu (1997:133-141) destaca o papel dos diferentes tipos de espiões para o conhecimento avançado dos planos do inimigo, das dificuldades do terreno, das movimentações e do estado de espírito das tropas.

21. Para uma análise bastante crítica sobre o significado da expressão "Revolução nos Assuntos Militares" (RMA), ver o capítulo final de Proença Jr., Diniz e Raza (1999); cf. também Vickers (1997). Sobre a RMA ocorrida com as guerras napoleônicas, ver Creveld (1985:58-102); cf., também, Jones (1987:320-386). Sobre inteligência e RMA nos dias de hoje, ver Fitzsimonds (1995).

22. Ver, também, para aspectos mais técnicos do problema, Boyes (1985).

23. Isso não quer dizer que a espionagem militar não fosse uma prioridade dos novos serviços. Casos como o do coronel Redl (espião russo na Áustria) e do Barão Schluga (espião alemão em Paris), logo antes da I Guerra Mundial, servem de lembrete contra simplificações acerca da natureza da inteligência militar. Além disso, o uso de redes extensas de fontes humanas para monitorar a mobilização e as linhas de comunicação e abastecimento nos territórios ocupados ("low level assets") também indica que não se tratava simplesmente de escolher entre fontes ostensivas e espionagem (cf. Richelson, 1995).

24. Para um relato histórico sobre os usos da inteligência na I Guerra Mundial, ver Richelson (1995:18-46). Para os problemas de avaliação (assessment) e as percepções de ameaça, ver May (1984:13-233).

25. Um comentário sobre Pearl Harbor, breve mas atualizado do ponto de vista historiográfico, pode ser encontrado em Richelson (1995:115-123). O tratamento analítico mais interessante sobre o episódio foi feito por Wohlstetter (1962).

26. A tradução mais adequada para joint seria conjunto, mas como no jargão militar brasileiro o termo conjunto indica uma articulação fraca ("cooperativa") entre as forças, fazendo com que o próprio estado-maior não seja capaz de unificar o comando das forças singulares em operações militares, preferi adotar aqui o termo integrado (seguido da expressão internacional original entre parênteses). Para uma justificativa adicional dessa prática, ver Proença Jr. e Diniz (1998:77-79, n. 6).

27. Países como a Costa Rica, que não têm Forças Armadas, poderiam ser uma exceção, mas isso dependeria de uma análise das capacidades de inteligência presentes em sua diplomacia, forças constabulares e polícia nacional. De todo modo, o problema da componente militar dos sistemas nacionais de inteligência parece-me mais afeito aos Estados mais poderosos do sistema internacional, incluindo potências regionais e países relevantes em diferentes "complexos de segurança" (cf. Buzan, Wæver e Wilde, 1998).

28. Para uma descrição detalhada das organizações militares de inteligência norte-americanas, ver Richelson (1999:55-129).

29. Na França, o policiamento organizado sob controle das autoridades centrais remonta à segunda metade do século XVII. Segundo Bayley (1975:343-345), a coleta de informações de segurança foi instituída já durante a Revolução Francesa, mas adquiriu uma expressão organizacional mais definida depois do 18 de Brumário. Para Charles Tilly: “Durante os anos iniciais da Revolução, as forças de polícia do Antigo Regime se dissolveram de forma geral quando os comitês populares, os guardas nacionais e os tribunais revolucionários assumiram suas atividades quoti- 


\section{Marco Cepik}

dianas. Todavia, com o Diretório, o Estado concentrou a fiscalização e apreensão numa organização isolada e centralizada. Fouché de Nantes tornou-se ministro da polícia em VII/1799 e, daí por diante, passou a existir um ministério cujos poderes se estenderam a toda a França e aos territórios conquistados. Na época de Fouché, a França havia se transformado num dos países mais policiados do mundo" (Tilly, 1996:174).

30. No caso dos Estados Unidos, por exemplo, até o final da II Guerra Mundial, o FBI controlava as operações de inteligência na América Latina. Mesmo após o fim da Guerra Fria, há considerável pressão para a atuação internacional do órgão em temas como terrorismo, proliferação de armas de destruição massiva, crime organizado, lavagem de dinheiro, crimes eletrônicos e tráfico de drogas. Em todas essas áreas há disputas jurisdicionais com a CIA, a DEA, o Secret Service e o INR. Para uma primeira avaliação das operações do FBI no exterior, ver Holt (1995:20-37).

31. Em nenhuma dessas atividades é fácil delimitar a jurisdição das polícias e dos serviços de inteligência. Duas diferenças são marcantes: a) tipicamente, enquanto as investigações criminais buscam elucidar a autoria de crimes e contravenções penais específicas, os alvos dos serviços de inteligência são atores e fenômenos mais abrangentes, os quais precisam ser conhecidos para que políticas públicas mais eficazes possam ser desenhadas. O produto final de uma investigação criminal é a instrução de um processo judicial, enquanto o produto de uma operação de inteligência é um relatório sobre o conhecimento adquirido; b) grosso modo, polícia cuida de problemas "internos" do país, enquanto inteligência está mais voltada para o "exterior".

32. Nos países que seguiam o modelo soviético (KGB), havia uma organização centralizada de inteligência e segurança, organizada em moldes militares, dividida em diretórios responsáveis por humint, contra-inteligência, inteligência de segurança, operações encobertas, sigint, infosec etc. A manutenção da ordem pública e a repressão política eram realizadas também pelas polícias e pelas tropas do Ministério do Interior (MVD). O modelo de organização do aparato de segurança e inteligência brasileiro durante o regime militar (1964-1985), baseado em uma agência central (SNI) que vertebrava um sistema nacional (SISNI), foi descrito por analistas como sendo mais próximo do modelo soviético do que dos modelos liberais ocidentais (cf. Stepan, 1988:19-20; ver, também, Bruneau, 2000:1-36).

33. Sobre as missões do FBI na área de inteligência doméstica (security intelligence), contra-inteligência e contraterrorismo, ver Watson (1995). Sobre as funções de inteligência policial e análise criminal, ver Peterson (2000).

34. Sobre as agências de inteligência do Japão, ver Hansen (1996).

35. Isso resulta do fato de as próprias polícias originarem-se em parte das Forças Armadas, a partir de uma bifurcação de missões que, na Europa, ocorreu em épocas muito diferentes em cada país. Na Inglaterra, essa divisão é clara desde o surgimento do atual modelo de policiamento civil, entre 1829 e 1889. As linhas militares de organização do trabalho policial predominam ainda hoje em muitos países, como a Itália, a França, a Rússia e o Brasil. Por outro lado, atualmente, a maioria das Forças Armadas tem organizações de segurança e contra-inteligência próprias, inclusive em nível ministerial, como é o caso do Defense Security Service - DSS, do Departamento de Defesa dos Estados Unidos. Embora essas organizações tenham 
como missão a proteção de segredos governamentais, o que as torna bastante próximas dos serviços de inteligência propriamente ditos, na medida em que existem trocas de experiência que beneficiam mutuamente as operações informacionais ofensivas e defensivas, elas não são formalmente consideradas como parte integrante dos sistemas nacionais de inteligência. Como foi mencionado acima, a principal organização departamental de inteligência do Departamento de Defesa dos Estados Unidos é a Defense Intelligence Agency - DIA. Em outros países, a contra-inteligência e a inteligência de segurança são ainda fortemente vinculadas à inteligência militar. Na Inglaterra atual, o serviço de inteligência de segurança é uma organização civil subordinada diretamente ao ministro do Interior.

36. Para um excelente tratamento do caso inglês em perspectiva comparada com os sistemas policiais da França, Alemanha e Itália, ver o texto de Bayley (1975:328-379).

37. Atualmente, o SIS é subordinado ao Foreign Office e o MI-5 é subordinado ao Home Office, que são, respectivamente, os Ministérios das Relações Exteriores e do Interior no governo britânico.

38. Esses percentuais sobre prioridades e alocações de recursos estão disponíveis em http://www.mi5.gov.uk.

39. Sobre os serviços de inteligência de segurança do Canadá, Inglaterra, Rússia, França e Estados Unidos, cf. Richelson (1988).

40. Em Israel, por exemplo, a principal instância de coordenação ainda é o comitê dos dirigentes das agências de inteligência, segurança e polícia, o Va'adat Rashei Hasherutim (VAADAT), que é coordenado pelo chefe do MOSSAD. Mas o gabinete do primeiro-ministro tem agora uma unidade própria de supervisão e definição de prioridades de coleta de informações (requirements), que coordena suas atividades com o VAADAT. No Brasil, a Agência Brasileira de Inteligência - ABIN é o órgão central e, do ponto de vista legal, coordena o Sistema Brasileiro de Inteligência - SISBIN. Embora a agência devesse ser ligada diretamente ao presidente da República, segundo os termos de sua lei de criação, na prática, a ABIN encontra-se subordinada ao Gabinete de Segurança Institucional-GSI da Presidência da República. A supervisão externa será feita, segundo a legislação em vigor em julho de 2000, pela Câmara de Relações Exteriores e Defesa Nacional - CREDEN do Conselho de Governo, no Poder Executivo, e por comissão mista da Câmara dos Deputados e do Senado Federal (cf. Antunes, 2002).

41. Os quatro sistemas nacionais de polícia analisados por David Bayley foram diferenciados em treze atributos: 1) maior ou menor extensão das tarefas formais, tais como a prevenção do crime e a fiscalização da cobrança de impostos; 2) maior ou menor extensão das tarefas informais, tais como a mediação de conflitos entre as partes; 3 ) a presença ou não de tarefas políticas, tais como a segurança do regime político, do governo ou mesmo a coleta de inteligência; 4) o grau de agregação da autoridade sobre as unidades do sistema (local ou nacional, descentralizada ou centralizada); 5) o número de forças policiais especializadas; 6) a esfera de controle político, se local ou nacional, e se a prestação de contas é feita para um corpo político representativo ou burocrático; 7) a esfera de controle legal, se a polícia se submete a um sistema legal unificado ou a cortes administrativas especiais; 8) se a carreira é unitária ou se é diferente para oficiais e para policiais / praças; 9) se o treinamento é predominantemente militar ou civil; 10) se a especialização funcional é alta ou 


\section{Marco Cepik}

baixa, por exemplo, em relação ao patrulhamento, investigação criminal, periciamento técnico, guarda de fronteiras, polícia fiscal etc.; 11) como a polícia é percebida pelo público em relação a temas como confiabilidade, autoritarismo, corrupção, eficiência etc.; 12) se o modo de intervenção policial é mais ou menos individualizado, mais ou menos formal; 13) dinâmicas do uso da força e de armamento. Embora os quatro casos sejam significativamente diferentes entre si, se fosse para tratar esses indicadores tipológicos como parte de um continuum, a Inglaterra de 1975 estaria em um extremo e a Itália em outro. Tomando como ponto de partida essa diferença, Bayley estuda por que as características decisivas dos sistemas de cada país se formam em diferentes períodos do processo moderno de desenvolvimento nacional e quais as variáveis independentes mais importantes na explicação dos atributos de cada caso nacional (cf. Bayley, 1975).

42. Um conjunto adicional de interações entre variáveis é utilizado pelo autor para explicar as diferenças entre os quatro casos. Em especial, Bayley destaca que as práticas de organização do poder anteriores ao momento de surgimento e amadurecimento dos sistemas nacionais de polícia influenciaram diretamente a abrangência das tarefas e o grau de centralização do sistema. A natureza da violência social existente, a presença ou não de uma forte resistência popular ao governo, a mudança nas demandas societais por lei e ordem como resultado da composição interna da população, a existência ou não de ortodoxias religiosas ou políticas, as reações das elites à incorporação e, finalmente, a própria posição internacional do país, de maior ou menor segurança internacional. Ao final do ensaio, Bayley levanta uma hipótese interessante sobre a tendência a uma maior convergência internacional dos padrões nacionais de organização, procedimentos e accountability no trabalho policial. Essa convergência seria muito mais clara em relação ao desempenho operacional, pois nesta área existem medidas e padrões relativamente internacionalizados (cf. Bayley, 1975:328-379).

43. Um trabalho clássico sobre a expansão do governo central nos Estados Unidos é o de Löwi (1979). Para uma exposição didática do funcionamento do sistema político dos Estados Unidos, ver Löwi e Ginsberg (1992). Os dados mencionados aqui são retirados de Stanley e Niemi (1995) e também de Banco Mundial (1997). Para dados comparativos sobre gastos governamentais que invalidam o núcleo da teoria da escolha pública sobre os "gastos excessivos", ver Przeworski (1995:85).

44. Para uma síntese das premissas neo-institucionalistas e de sua aplicação ao estudo das burocracias domésticas de serviços e de regulação, ver Moe (1990).

45. No capítulo 1 ("Towards a Theory of National Security Agencies"), além do tema principal sobre a necessidade de reformular o modelo neo-institucionalista para dar conta das diferenças entre agências domésticas de políticas públicas e agências de segurança nacional, Zegart também faz comentários úteis, embora incidentais, sobre as diferenças entre o novo institucionalismo e a abordagem da política burocrática (Allison, 1971). O esquema analítico de Zegart é ousado e de modo geral bastante consistente, mas três aspectos me pareceram muito problemáticos. Primeiro, seu ponto de partida para propor um modelo de agências de segurança nacional é uma crítica superficial e absolutamente equivocada ao "realismo" na área de Relações Internacionais. Além de errada, sua crítica é fútil, pois não tem nenhuma função posterior na construção do modelo. Em segundo lugar, é problemática sua 
suposição de que os presidentes, ao contrário dos legisladores e dos burocratas, são mais protegidos do assédio dos grupos de interesses e têm mais incentivos para concentrarem-se em grandes temas nacionais. Afinal, esses incentivos não surtiram muitos efeitos em alguns dos presidentes norte-americanos que mais influenciaram o desenho organizacional das agências de segurança nacional (e.g. Truman, Reagan e Clinton). A própria caracterização dos presidentes como agentes perfeitos do público e vítimas indefesas do poder dos burocratas é claramente demasiada. Finalmente, a excessiva preocupação de Zegart em não parecer "funcionalista" e concentrar sua explicação nas preferências e constrangimentos institucionais dos agentes, fez com que seu modelo subestimasse a um ponto inaceitável o conhecimento sobre o que as agências realmente "fazem", ignorando as funções exercidas e os requisitos tecnológicos como fatores explicativos sobre o desenho organizacional das agências de segurança nacional. Além desses três problemas mais sérios, o critério de diferenciação entre agências domésticas e agências de segurança nacional baseado no grau de interdependência burocrática ("degree of bureaucratic interconectedness") me parece exigir maior especificação, pois a falta de delimitação clara de jurisdição entre agências ocorre também - e talvez em graus mais elevados - em setores da burocracia no ambiente interno (e.g. atividades urbanas ou planejamento governamental). O último ponto é que sua pretensão (explicitada na Conclusão do livro) de estar fundando as bases para uma "teoria geral da burocracia" parece esbarrar nos problemas mencionados e também na necessidade de muitos estudos comparativos em escala internacional (cf. Zegart, 1999:12-53 e 223-236).

46. Os dados sobre grupos de interesse utilizados por Amy Zegart são resultado de pesquisas sobre associativismo civil, lobbies no Congresso e fontes de financiamento de campanhas de deputados. Os grupos de interesse na área de segurança nacional são mais recentes: enquanto $75 \%$ dos Think Tanks de política internacional e dos escritórios de lobby na área de defesa sediados em Washington, D.C., começaram a operar na década de 70, organizações ambientalistas como o Sierra Club (1892), associações empresariais como a National Association of Manufacturers (1892) e grupos de pressão temáticos como a National Education Association (1857) são muito mais consolidadas. Os grupos de interesse na área de segurança nacional são menos numerosos: em 1990, de um total de 9.138 grupos de pressão atuando sobre o Congresso dos Estados Unidos, 922 eram de alguma forma relacionados com assuntos internacionais. Os grupos da área de saúde sozinhos eram mais numerosos (1.054) do que os de política externa. Em terceiro lugar, grupos de interesse na área de segurança nacional investem menos nas campanhas dos congressistas membros dos comitês de sua área. Segundo Zegart, enquanto um membro do Senate Committee on Banking recebia em média 29\% dos recursos para campanha de doadores de fundos relacionados ao setor bancário, um membro do Senate Committee on Armed Services recebia apenas $6 \%$ dos fundos de sua campanha de doadores com interesses no setor (cf. Zegart, 1999:22-27 e 239-240).

47. As diferenças existentes entre as burocracias de segurança nacional (NSC, JCS e CIA) desdobram-se na diversidade interna dos próprios sistemas de inteligência (CIA, FBI, DIA etc.). Os padrões de desenvolvimento dos sistemas nacionais de inteligência refletem também essas diferenças entre os vários tipos de organizações de inteligência, bem como suas diferenças em relação às Forças Armadas, polícias, serviço diplomático ou instâncias de formulação de políticas (tais como os staffs 


\section{Marco Cepik}

dos Conselhos Nacionais de Segurança). Entre os dois tipos extremos de organizações governamentais, Zegart aponta a necessidade de incorporar a uma teoria geral da burocracia uma vasta quantidade de agências que ficariam a meio caminho no espectro burocrático. Em particular, seria interessante ver como se posicionam no modelo as organizações de política econômica que atravessam a dicotomia externo/interno (Bancos Centrais, Comércio Exterior, Conselhos de Política Econômica etc.) (cf. Zegart, 1999:233).

48. Para uma escala comparativa (muito limitada) entre (poucos) casos nacionais que situa as posições de cada país ao longo de um continuum e não de forma polar, ver Johnson (1996:119-145).

49. Para uma descrição sumária dos sistemas de inteligência de países selecionados, ver www.fas.org/irp. Sobre características operacionais e problemas de gestão e reforma, ver Berkowitz e Goodman (2000) e também Herman (2001).

50. A formulação de James $Q$. Wilson é uma resposta direta às abordagens predominantes sobre o comportamento dos burocratas derivadas da teoria da escolha pública ( $p$ ublic choice theory). Cada autor define a autonomia das agências governamentais de acordo com sua premissa sobre o que quer que sejam as preferências fundamentais dos burocratas: maximização de orçamentos, de recursos organizacionais, de prestígio, de remuneração pessoal, de estabilidade funcional, "bureau shaping", jurisdição indisputada etc. De todas essas, a mais plausível parece ser a de Wilson (autonomia), na medida em que consiste em uma suposição substantiva sobre as preferências dos burocratas (atendendo assim à exigência metodológica da economia neoclássica sobre o confinamento dessas suposições ao lado da oferta), ao mesmo tempo que essa suposição consiste em afirmar a busca de autonomia como uma precondição para outras preferências endogenamente formadas nas próprias interações conflitivas. Sobre a autonomia e a racionalidade desses "bureaucratic turfs", ver Wilson (1989). A posição de Wilson sobre a autonomia burocrática é, nesse aspecto, compatível com as posições de Adam Przeworski ("o Estado é 'autônomo' quando ele formula suas próprias metas e as realiza em face à oposição") e do próprio Samuel Huntington ("institucionalização política, no sentido de autonomia, significa o desenvolvimento de organizações e procedimentos políticos que não sejam apenas expressões dos interesses de grupos sociais determinados"). Para uma "explicação" do crescimento institucional baseada na postulação de que burocratas maximizam orçamentos e ofertam níveis excessivos de serviço (subótimos para o público) porque são precariamente supervisionados, ver dois textos seminais da public choice: Niskanen (1977) e também Buchanan (1977). Para uma exposição didática das diversas ramificações dessa literatura, ver Parsons (1995:306-323). Para uma crítica da explicação da autonomia estatal feita pela corrente principal da public choice, ver Przeworski (1995:77-85). Para uma crítica do modelo "maximizador de orçamentos" e a formulação alternativa de um modelo explicativo do "crescimento institucional" baseado nas alternativas estratégicas e nos dilemas de ação coletiva dos burocratas ("bureau-shaping model"), ver Dunleavy (1991:147-259).

51. Se as agências governamentais conseguem garantir razoavelmente sua autonomia, então elas provavelmente vão tentar obter mais recursos ou ampliar sua jurisdição. O problema, segundo James Wilson, é que isso envolve um enorme "se" condicio- 
nal: “Conflitos interburocráticos não eram um problema tão grande quando as únicas agências federais importantes eram os Correios, o Bureau de Pensões e a Receita Federal. Conflitos interburocráticos tendem a ser um problema enorme e em grande medida insolúvel quando o governo é composto por dezenas de agências que fazem política externa, outras tantas responsáveis pela política econômica ou que a afetam diretamente, bem como por um sem-número de organizações que regulam a atividade privada e garantem o cumprimento das leis criminais" (Wilson, 1989:195). Disputas interburocráticas não são insanáveis e tampouco são irracionais, apenas são difíceis porque envolvem aspectos vitais da identidade e das preferências de atores políticos organizados.

\section{REFERÊNCIAS BIBLIOGRÁFICAS}

ALLISON, Graham T. (1971), The Essence of Decision: Explaining the Cuban Missile Crisis. New York, Harper Collins.

ALMOND, Gabriel e POWELL JR., G. Bingham. (1966), Comparative Politics: A Developmental Approach. Boston, Little Brown and Company.

ANDREW, Christopher. (1984), "France and the German Menace", in E. R. May (ed.), Knowing One's Enemies: Intelligence Assessment Before the Two World Wars. Princeton, NJ, Princeton University Press, pp. 127-149.

ANTUNES, Priscila C. B. (2002). SNI e ABIN: Uma Leitura da Atuação dos Serviços Secretos Brasileiros ao longo do Século XX. Rio de Janeiro, Fundação Getulio Vargas Editora.

ARRIGHI, Giovanni. (1996), O Longo Século XX: Dinheiro, Poder e as Origens de Nosso Tempo. São Paulo, UnESP.

BANCO MUNDIAL. (1997), O Estado num Mundo em Transformação/Relatório sobre o Desenvolvimento Mundial. Washington, DC, World Bank Group.

BAYLEY, David H. (1975), "The Police and Political Development in Europe", in C. Tilly (ed.), The Formation of National States in Western Europe. Princeton, NJ, Princeton University Press, pp. 328-379.

BERKOWITZ, Bruce e GOODMAN, Allan. (2000), Best Truth: Intelligence in the Information Age. New Haven, CT, Yale University Press.

BOBBIO, Norberto. (1986), O Futuro da Democracia: Uma Defesa das Regras do Jogo. Rio de Janeiro, Paz e Terra.

(1989), "Público/Privado", in Enciclopédia Einaudi [Estado-Guerra]. Lisboa, Imprensa Nacional/Casa da Moeda, vol. 14.

. (2000), "Democracia e Segredo", in N. Bobbio e M. Bovero (orgs.), Teoria Geral da Política: A Filosofia Política e as Lições dos Clássicos. Rio de Janeiro, Campus, pp. 399-415. 


\section{Marco Cepik}

BOYES, Jon L. (ed.). (1985), Issues in $C^{3}$ I Program Management: Requirements, Systems and Operations. Washington, DC, AFCEA Press.

BRINT, Steven e KARABEL, Jerome. (1991), "Institutional Origins and Transformations: The Case of American Community Colleges", in W. W. Powell e P. J. DiMaggio (eds.), The New Institutionalism in Organizational Analysis. Chicago, The University of Chicago Press, pp. 337-360.

BRUNEAU, Thomas C. (2000), "Intelligence and Democratization: The Challenge of Control in New Democracies". International Journal of Intelligence and Counterintelligence, vol. $14, \mathrm{n}^{\circ} 3$.

BUCHANAN, J. M. (1977), “Why Does Government Grow?”, in T. Borcherding (org.), Budgets and Bureaucrats: The Sources of Government Growth. Durham, NC, Duke University Press.

BUZAN, Barry, WÆVER, Ole e WILDE, Jaap de. (1998), Security: A New Framework for Analysis. Boulder, CO, Lynne Rienner Publishers.

COAKLEY, Thomas P. (ed.). (1991), C ${ }^{3}$ I: Issues of Command and Control. Washington, DC, NDU Press.

CREVELD, Martin Van. (1985), Command in War. Cambridge, MA, Harvard University Press.

DANDEKER, C. (1990), Surveillance, Power and Modernity: Bureaucracy and Discipline from 1700 to the Present Day. Cambridge, UK, Polity Press.

DERIAN, James Der. (1992), Anti-Diplomacy: Spies, Terror, Speed and War. Oxford, Blackwell.

. (1993), "Anti-Diplomacy, Intelligence Theory and Surveillance Practice". Intelligence and National Security, vol. 8, nํㅜ 3, pp. 29-51.

DEUTSCH, Karl W. (1966), The Nerves of Government: Models of Political Communication and Control. New York, Free Press.

DUNLEAVY, Patrick. (1991), Democracy, Bureaucracy \& Public Choice. London, Harvester Wheatsheaf.

_ O O'LEARY, Brendam. (1987), Theories of the State: The Politics of Liberal Democracies. London, MacMillan Press.

ELSTER, Jon. (1994), Peças e Engrenagens das Ciências Sociais. São Paulo, Relume-Dumará.

FISCHER, Ben B. (1997), OKHRANA: The Paris Operations of the Russian Imperial Police. Monografia não classificada do Center for the Study of Intelligence at CIA. Disponível em: <http://www.cia.gov/csi/monograph>.

FITZSIMONDS, James R. (1995), “Intelligence and the Revolution in Military Affairs”, in R. Godson, G. Schmitt e E. May (eds.), U.S. Intelligence at the Crossroads: Agendas for Reform. New York, Brassey's, pp. 265-287.

GALEOTTI, Mark. (1996), The Kremlin's Agenda. London, Jane's Intelligence Review Press. 
GIDDENS, Anthony. (1987), The Nation-State and Violence. Berkeley, University of California Press.

GILL, Peter. (1994), Policing Politics: Security Intelligence and the Liberal Democratic State. London, Frank Cass.

GODSON, Roy (ed.). (1988), Comparing Foreign Intelligence: The U.S., the USSR, the U.K. $\mathcal{E}$ the Third World. London, Pergamon-Brassey's.

e ROBERTSON, Kenneth G. (eds.). (1987), British and American Approaches to Intelligence. New York, St. Martin's.

GOLDSTEIN, R. J. (1983), Political Repression in Nineteenth-Century Europe. London, Croom Helm.

GOODIN, Robert E. (ed.). (1996), The Theory of Institutional Design. Cambridge, UK, Cambridge University Press.

_e KLINGEMANN, Hans-Dieter. (2000), A New Handbook of Political Science. Oxford, UK, Oxford University Press.

HABERMAS, Jürgen. (1994), The Structural Transformation of the Public Sphere: An Inquiry into a Category of Burgeois Society. Cambridge, MA, MIT Press.

HALL, Peter e TAYLOR, Rosemary. (1996), Political Science and the Three Institutionalisms. Mimeo (editado posteriormente em Political Studies).

HANSEN, James H. (1996), Japanese Intelligence: The Competitive Edge. Washington, DC, NIBC Press.

HASTED, Glenn P. (1991), “Towards the Comparative Study of Intelligence". Conflict Quarterly, summer, pp. 55-72.

HERMAN, Michael. (1996), Intelligence Power in Peace and War. Cambridge, Cambridge University Press.

_. (2001), Intelligence Services in the Information Age. London, Frank Cass.

HINSLEY, F. H. (1993), British Intelligence in the Second World War (abridged edition). London, HMSO.

HOLT, Pat M. (1995), Secret Intelligence and Public Policy: A Dilemma of Democracy. Washington, DC, Congressional Quarterly Press.

HUNTINGTON, Samuel P. (1975) [1968], A Ordem Política nas Sociedades em Mudança. São Paulo, Forense.

JESSOP, B. (1990), State Theory: Putting Capitalist States in their Place. Cambridge, Polity Press.

JOHNSON, Loch K. (1996), Secret Agencies: U.S. Intelligence in a Hostile World. New Haven, CT, Yale University Press.

JONES, Archer. (1987), The Art of War in the Western World. Oxford, Oxford University Press.

KAHN, David. (1996), The Codebreakers: The Comprehensive History of Secret Communication from the Ancient Times to the Internet. New York, Scribner. 


\section{Marco Cepik}

KENNEDY, Paul. (1989), Ascensão e Queda das Grandes Potências. Rio de Janeiro, Campus.

KNIGHT, Amy. (1996), Spies without Cloaks: The KGB's Successors. Princeton, NJ, Princeton University Press.

LIMONGI, Fernando. (1994), “O Novo Institucionalismo e os Estudos Legislativos: A Literatura Norte-Americana Recente". BIB - Boletim Informativo e Bibliográfico de Ciências Sociais, no 37, 1ํㅗ., sem. pp. 3-38.

LÖWI, Theodore. (1979), The End of Liberalism (2 ${ }^{\mathrm{a}}$ ed.). New York, W.W. Norton.

_ e GINSBERG, Benjamin. (1992), American Government. New York, W. W. Norton.

LYMAN, Michael D. (1999), The Police: An Introduction. Upper Saddle River, NJ, Prentice Hall.

MARCH, James G. e OLSEN, Johan P. (1984), "The New Institutionalism: Organizational Factors in Political Life". American Political Science Review, vol. 78, nํ3, pp. 734-749.

. (1989), Rediscovering Institutions: The Organizational Basis of Politics. New York, Free Press.

MAY, Ernest R. (ed.). (1984), Knowing One's Enemies: Intelligence Assessment Before the Two World Wars. Princeton, NJ, Princeton University Press.

MELO, Carlos Ranulfo Félix. (1999), Retirando as Cadeiras do Lugar: Migração Partidária na Câmara dos Deputados (1985-1998). Tese de Doutorado, Universidade Federal de Minas Gerais - UFMG.

MOE, Terry. (1990), "The Politics of Structural Choice: Toward a Theory of Public Bureaucracy", in O. E. Williamson (ed.), Organizational Theory: From Chester Barnard to the Present and Beyond. New York, Oxford University Press.

NISKANEN, W. A. (1977), Bureaucracy and Representative Government. Chicago, Aldine Atherton.

NORTH, Douglass C. (1990), Institutions, Institutional Change and Economic Performance. New York, Cambridge University Press.

OSTROM, Elinor. (1990), Governing the Commons: The Evolution of Institutions for Collective Action. New York, Cambridge University Press.

. (1991), "Rational Choice Theory and Institutional Analysis: Toward Complementarity". American Political Science Review, vol. 85, no 1, pp. 237-243.

PARRISH, Michael. (1991), Soviet Security and Intelligence Organizations (1917-1990): A Biographical Dictionary and Review of Literature in English. Westport, CT, Meckler Corp.

PARSONS, Wayne D. (1995), Public Policy: An Introduction to the Theory and Practice of Policy Analysis. London, Elgar Pub.

PERROW, Charles. (1986) [1972], Complex Organizations: A Critical Essay (3ㅜㅡㄹ. ed.). San Francisco, CA, McGraw-Hill.

PETERSON, Marilyn (ed.). (2000), Intelligence 2000: Revising the Basic Elements. Sacramento, CA, IALEIA/LEIU. 
PETTIT, Philip. (1996), "Institutional Design and Rational Choice", in R. E. Goodin (ed.), The Theory of Institutional Design. Cambridge, UK, Cambridge University Press.

POGGI, Gianfranco. (1978), A Evolução do Estado Moderno: Uma Introdução Sociológica. Rio de Janeiro, Zahar.

POLMAR, Norman e ALLEN, Thomas B. (1997), Spy Book: The Encyclopedia of Espionage. New York, Random House.

POWELL, Walter W. e DIMAGGIO, Paul J. (eds.). (1991), The New Institutionalism in Organizational Analysis. Chicago, The University of Chicago Press.

PRATES, Antônio Augusto. (2000), “Organização e Instituição no Novo Institucionalismo". Teoria \& Sociedade, no 5, pp. 123-146.

PROENÇA JR., Domício e DINIZ, Eugênio. (1998), Política de Defesa no Brasil: Uma Análise Crítica. Brasília, Ed. UnB. e RAZA, Salvador. (1999), Guia de Estudos de Estratégia. Rio de Janeiro, Jorge Zahar.

PRZEWORSKI, Adam. (1995), Estado \& Economia no Capitalismo. Rio de Janeiro, Relume-Dumará.

PUTNAM, Robert. (1996), Comunidade e Democracia: A Experiência da Itália Moderna. Rio de Janeiro, Fundação Getulio Vargas Editora.

RICHELSON, Jeffrey T. (1986), Sword and Shield: Soviet Intelligence and Security Apparatus. Cambridge, UK, Ballinger Publishing Company.

. (1988), Foreign Intelligence Organizations. Cambridge, MA, Ballinger Publishing Company.

(1995), A Century of Spies: Intelligence in the Twentieth Century. Oxford, Oxford University Press.

. (1999), The U.S. Intelligence Community (4⿳亠丷厂 ed.). Cambridge, MA, Ballinger Publishing Company.

_ e BALL, Desmond. (1985), The Ties that Bind: Intelligence Cooperation between the UKUSA Countries. Boston, Allen \& Unwin.

SPRUYT, Hendrik. (1996), The Sovereign State and Its Competitors (2 $2^{\mathrm{a}}$ ed.). Princeton, NJ, Princeton University Press.

STANLEY, Harold W. e NIEMI, Richard G. (1995), Vital Statistics on American Politics (5 ed.). Washington, DC, Congressional Quarterly Press.

STEINMO, Sven, THELEN, Kathleen e LONGSTRETH, Frank (eds.). (1992), Structuring Politics: Historical Institutionalism in Comparative Analysis. Cambridge, Cambridge University Press.

STEPAN, Alfred. (1988), Rethinking Military Politics: Brazil and the Southern Cone. Princeton, NJ, Princeton University Press.

STRAYER, Joseph. (1970), On the Medieval Origins of the Modern State. Princeton, NJ, Princeton University Press.

SUN TZU. (1997), A Arte da Guerra. Rio de Janeiro, Paz e Terra. 


\section{Marco Cepik}

THOMPSON, James W. e PADOVER, Saul K. (1965), Secret Diplomacy, Espionage and Cryptography: 1500-1815. New York, Ungar Publisher.

THOMSON, Janice E. (1995), "State Sovereignty in International Relations: Bridging the Gap Between Theory and Empirical Research". International Studies Quarterly, no 39 , pp. 213-233.

TILLY, Charles. (1975), "Western State Making and Theories of Political Transformation", in C. Tilly (ed.), The Formation of National State in Western Europe. Princeton, NJ, Princeton University Press.

. (1985), "War Making and State Making as Organized Crime", in P. B. Evans, D. Rueschemeyer e T. Skocpol (orgs.), Bringing the State Back In. Cambridge, Cambridge University Press, pp. 169-191.

. (1996), Coerção, Capital e Estados Europeus: 990-1992. São Paulo, EdusP.

VICKERS, Michael J. (1997), “The Revolution in Military Affairs and Military Capabilities", in R. L. Pfaltzgraff Jr. e R. H. Shultz Jr. (eds.), War in Information Age: New Challenges for U.S. Security. Washington/London, Brassey's.

WATSON, Patrick. (1995), "The FBI's Changing Mission”, in R. Godson, G. Schmitt e E. MAY (eds.), U.S. Intelligence at the Crossroads: Agendas for Reform. New York, Brassey's, pp. 146-153.

WEBER, Max. (1993) [1918], Parlamento e Governo na Alemanha Reordenada. Petrópolis, RJ, Vozes.

WILSON, James Q. (1989), Bureaucracy: What Government Agencies Do and Why they Do It. New York, Basic Books.

WOHLSTETTER, Roberta. (1962), Pearl Harbor: Warning and Decision. Stanford, CA, Stanford University Press.

WOLF, Marcus e MCELVOY, Anne. (1997), O Homem sem Rosto. Rio de Janeiro, Record.

YOUNG, Robert J. (1984), "French Military Intelligence and Nazi Germany, 1938-1939", in E. R. May (ed.), Knowing One's Enemies: Intelligence Assessment Before the Two World Wars. Princeton, NJ, Princeton University Press, pp. 271-309.

ZEGART, Amy. (1999), Flawed by Design: The Evolution of the CIA, JCS and NSC. Stanford, CA, Stanford University Press. 


\section{ABSTRACT \\ National Intelligence Systems: Origins, Expansion Logic, and Current Configuration}

This article analyzes the formation of national intelligence systems in the modern state and the basic causes of institutional differences even among countries from the same constitutional tradition, like the United Kingdom and the United States. Considering intelligence systems as a sort of bureaucracy typically associated with the state's coercive core, one can trace their origins to three different historical matrices: $16^{\text {th }}$ and $17^{\text {th }}$ century European diplomacy, the Napoleonic form of war management at the turn from the $18^{\text {th }}$ to the $19^{\text {th }}$ century, and $19^{\text {th }}$ and $20^{\text {th }}$ century counterrevolutionary political policing. Following a logic of expansion and functional differentiation that is simultaneously horizontal and vertical, current national intelligence systems display great organizational complexity and dilemmas in their institutionalization which provide good examples of the virtual impossibility of complete democratization of the state in the contemporary world.

Key words: institutions; state-building; war; intelligence services; bureaucracy

\section{RÉSUMÉ}

Systèmes Nationaux de Renseignements: Origine, Logique de Diffusion et Configuration Actuelle

Dans cet article, on analyse le processus de formation des systèmes nationaux de renseignements dans les États modernes ainsi que les causes des différences institutionnelles rencontrées même entre des pays dont la tradition constitutionnelle est semblable, comme la Grande-Bretagne et les États-Unis. Posés comme un type de bureaucratie propre au noyau coercitif de l'État, les services de renseignements surgissent à partir de trois modèles historiques: la diplomatie des $\mathrm{XVI}^{\mathrm{e}}$ et $\mathrm{XVII}{ }^{\mathrm{e}}$ siècles, le mode napoléonien de gestion de la guerre dans le passage $\mathrm{du} X \mathrm{XIII}^{\mathrm{e}}$ au XIXe siècle, et la surveillance politique anti-révolutionnaire des $\mathrm{XIX}^{\mathrm{e}}$ et $X X^{\mathrm{e}}$ siècles. Tout en suivant une logique de diffusion et de différenciation fonctionnelle, horizontale et verticale à la fois, les systèmes nationaux de renseignements de nos jours présentent une grande complexité organisationnelle, avec des dilemmes d'institutionnalisation qui montrent l'impossibilité d'une démocratisation pleine de l'État dans le monde d'aujourd'hui.

Mots-clé: institutions; construction de l'État; guerre; services de renseignements; bureaucratie 